\title{
Nocturnal boundary layer turbulence regimes analysis during the BLLAST campaign
}

\author{
Jesús Yus-Díez ${ }^{1,5}$, Mireia Udina ${ }^{1}$, Maria Rosa Soler ${ }^{1}$, Marie Lothon $^{2}$, Erik Nilsson ${ }^{3}$, Joan Bech ${ }^{1}$, and Jielun Sun ${ }^{4}$ \\ ${ }^{1}$ Departament de Física Aplicada - Meteorologia, Universitat de Barcelona, \\ C/Martí i Franquès, 1, 08028, Barcelona, Spain \\ ${ }^{2}$ Laboratoire d'Aérologie, University of Toulouse, CNRS, France \\ ${ }^{3}$ Department of Earth Sciences, Uppsala University, Uppsala, Sweden \\ ${ }^{4}$ NorthWest Research Associates, Boulder, Colorado, USA \\ ${ }^{5}$ Institute of Environmental Assessment and Water Research (IDAEA-CSIC), \\ C/Jordi Girona 18-26, 08034, Barcelona, Spain
}

Correspondence: Jesús Yus-Díez (jesus.yus@idaea.csic.es), Mireia Udina (mudina@meteo.ub.edu)

Received: 17 December 2018 - Discussion started: 1 March 2019

Revised: 19 June 2019 - Accepted: 2 July 2019 - Published: 26 July 2019

\begin{abstract}
A night-time turbulence regime classification, the so-called "HOckey-Stick Transition " (HOST) theory, proposed by Sun et al. (2012) from the Cooperative Atmosphere-Surface Exchange Study-1999 (CASES-99) is explored using data from the Boundary-Layer Late Afternoon and Sunset Turbulence (BLLAST) field campaign which took place during summer 2011 in the central French Pyrenean foothills.

Results show that the HOST turbulence relationships for the BLLAST field campaign data are strongly dependent on both the meteorological and orographic features. The HOST pattern only appears for nights when a stably stratified boundary layer can be developed, corresponding to fairweather and clear-sky nights, when the flow is generated by the nearby orography, from the south and the south-east. Those flows strongly influenced by the orography may generate intermittent or enhanced turbulence. When considering the whole nocturnal dataset for these flow directions, several enhanced turbulence points are found to be associated with sudden wind speed and directional shear transitions. In contrast, flows from other directions do not reproduce the HOST relationships and the turbulence relationship is almost linear, independent of vertical temperature gradients, corresponding to flows driven by synoptic scales. In addition we identify examples of gravity waves and top-down turbulent events that lead to transitions between the turbulence regimes.
\end{abstract}

\section{Introduction}

With the aim to investigate and categorize turbulence patterns generated by wind shear in the atmospheric stable boundary layer (SBL), Sun et al. (2012) analysed a month-long dataset collected in Kansas from the Cooperative AtmosphereSurface Exchange Study-1999 (CASES-99) in October 1999 (Poulos et al., 2002). They found that, depending on the relationship between the turbulence intensity of the flow and the wind velocity, turbulent mixing from the surface to the last level of measurement $(55 \mathrm{~m})$ can be categorized in three regimes (Fig. 1). A regime (regime 1) occurring when the wind speed $(V)$ is less than a threshold value $\left(V_{\mathrm{T}}\right)$, characterized by low turbulence intensity increasing slightly with the velocity. This is the weak turbulence regime, which is generated by local shear and modulated by the vertical temperature gradients of the SBL. Eddies generated by local shear, $\delta V / \delta z$, do not interact with the ground as their length scale is smaller than the observation height $z, \delta z<z$ (Sun et al., 2012). When $V>V_{\mathrm{T}}$ regime 2 occurs and turbulence is mainly driven by the bulk shear, therefore increasing strongly and nearly linearly with $V$. The close relationship between turbulence intensity and mean wind speed suggests that turbulence under moderate winds responds to the bulk shear $V(z) / z$ near the ground (Sun et al., 2012, 2016). The eddies dominating this stronger turbulence regime have a larger scale of $z$, leading to a well-mixed layer below this height and producing a near-neutral stratification. The value of the 


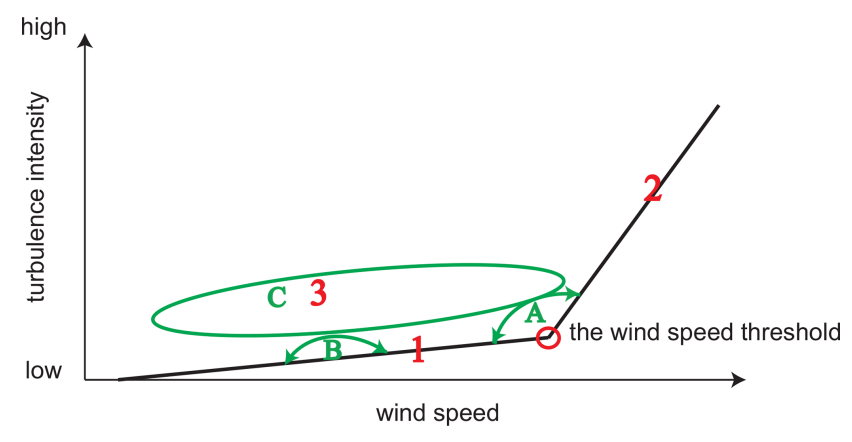

Figure 1. Schematic representation of the HOckey-Stick transition (HOST) theory with the three turbulence regimes (regime 1, 2, and 3 ) and the three turbulence intermittency categories (category A, category B, and category C). Reproduced from Fig. 2 of Sun et al. (2012) (CAmerican Meteorological Society. Used with permission.

wind speed threshold at which the shear changes from local to bulk increases approximately logarithmically with height (Sun et al., 2012; Bonin et al., 2015). In addition to these two turbulent regimes generated by the local or the bulk shear, moderate turbulence can often be generated for relative low values of $V$ and large stability conditions above the observation level by different coherent structures, for instance Kelvin-Helmholtz instabilities (Newsom and Banta, 2003), gravity waves (Sun et al., 2004; Udina et al., 2013), and density currents (Sun et al., 2002; Viana et al., 2010; Soler et al., 2014) that can generate turbulence, which is transported downward, toward observation levels where the wind speed is lower than the threshold value. This top-down turbulent regime is defined as regime 3, which also includes turbulence enhanced by wind shear associated with topographical features leading to flow accelerations, directional wind shear, and sub-meso motions (Mahrt et al., 2013). All of these intermittent turbulent events have the non-stationarity of the flow in common.

The schematic representation of the transition between the weak and the strong turbulence regimes resembles a hockey stick (Fig. 1) - this is why this theory is named the "HOckeyStick transition" (HOST). It can be explained in terms of total turbulence energy (TTE), which is defined as the sum of the turbulent kinetic energy (TKE) and the turbulent potential energy (TPE, also called available potential energy) (Zilitinkevich et al., 2007). As shown in Sun et al. (2016), if the vertical variation of the TTE is small, the turbulence shear production controls the variation of the TTE. When $V<V_{\mathrm{T}}$, the vertical transport of cold air is confined near the surface, and the stable stratification of the flow increases. Therefore, more turbulence energy is used to increase the TPE (Lin and Pao, 1979), and the TKE does not increase significantly with increasing $V(z)$. This situation corresponds to regime 1 . However, if $V>V_{\mathrm{T}}$, the stable stratification is considerably reduced, leading to a near-neutral regime. As a consequence, shear generates TKE as the TTE is not consumed to increase the TPE; this situation corresponds to regime 2.

The HOST theory represents a new approach for the turbulence parameterization in the surface layer, as the MoninObukhov similarity theory (MOST) may be limited, because the bulk formulae are only applicable within a near thin surface layer (Sun et al., 2012, 2016). The theory has been previously studied in other campaigns and for other sites in relatively flat terrain. Mahrt et al. (2013) studied the turbulence behaviour at three sites with different surface roughness, showing that the wind speed threshold decreases with increasing roughness length; Andreae et al. (2015) explored the three turbulence regimes and characterized the nocturnal boundary layer using data from the Amazon Tall Tower Observatory (ATTO); Bonin et al. (2015) used the HOST via remote sensing in the southern Great Plains; and Acevedo et al. (2016) studied the HOST theory via the contrasting structures of the stable and neutral states of the boundary layer over snow-covered surfaces. The theory has also been investigated using large-eddy simulation (LES) models (Udina et al., 2016), revealing the LES difficulties with respect to reproducing regime 1 .

As the HOST was originally derived from measurements taken in a relatively flat area, where the CASES-99 field campaign was held (Sun et al., 2012), the aim of this study is to explore the validity of the HOST theory in an area with complex terrain, for flows that are influenced by the nearby orography. This study considers nocturnal boundary layers with special emphasis on the very stable boundary layer. The data analysed herein are from the Boundary-Layer Late Afternoon and Sunset Turbulence (BLLAST) campaign (Lothon et al., 2014), which took place during early summer 2011 in France, on the "Plateau de Lannemezan", north of the central French Pyrenean foothills.

The structure of the paper is as follows. The site, the in situ observations of near-surface turbulence obtained from the array of instruments, and the data processing method applied are described in Sect. 2. The wind flow and wind regimes affecting the site during the BLLAST field experiment are analysed in Sect. 3. The categorization of the turbulence regime patterns for the BLLAST field campaign is investigated in Sects. 4 and 5, and the transition between regimes is illustrated in Sect. 6 using selected examples. A summary and the main conclusions are given in Sect. 7.

\section{Site, observations, and data processing}

Data used in this study are from the BLLAST field campaign conducted in early summer, from 14 June to 8 July 2011 in France around the Centre for Atmospheric Research (CRA, Centre de Recherches Atmosphériques) (Lothon et al., 2014). The site ("Site 1" in Fig. 2a) is located on the "Plateau de Lannemezan", which is a plateau over the Garonne Basin at about $600 \mathrm{~m}$ a.s.l. (above sea level). The 
plateau is about $11 \mathrm{~km}$ north of the base of the first range of the Pyrenees with peaks of around $1500-2000 \mathrm{~m}$ a.s.l. and is about $40 \mathrm{~km}$ from the highest peaks of the Pyrenees mountain range.

The site is influenced by both the steep orography surrounding it to the south-west (Pic du Midi de Bigorre) as well as the exit of the Aure Valley (Aura in local Occitan language) that is around $11 \mathrm{~km}$ to the south. The upper Garonne Valley is to the east-southeast (Fig. 2a).

The main objective of the BLLAST field campaign was to improve the knowledge of the afternoon and evening transition in the boundary layer (BL) (Lothon et al., 2014). To achieve this, a dense array of instrumentation was deployed over the area, although only some of the measurements are employed herein (Table 1). We focus the analysis on the data from the $10 \mathrm{~m}$ mast at surface site 2 (ss2), called Skinflow mast, and the $60 \mathrm{~m}$ tower placed at surface site 4 (ss4), called Valimev tower (Fig. 2b). From the Skinflow mast we use data from the sensors located at 2.23, 3.23, 5.27, and $8.22 \mathrm{~m}$ (hereafter $z_{2 \mathrm{~m}}, z_{3 \mathrm{~m}}, z_{5 \mathrm{~m}}$, and $z_{8 \mathrm{~m}}$, respectively), although the $z_{2 \mathrm{~m}}$ level is omitted when the values are very close to those of $z_{3 \mathrm{~m}}$. From the Valimev tower we use data from the sensors located at $29.4,45.8$, and $61.4 \mathrm{~m}$ (hereafter $z_{30 \mathrm{~m}}, z_{45 \mathrm{~m}}$, and $z_{600 \mathrm{~m}}$, respectively), see Table 1 .

As the analysis is restricted to night-time, we only consider data measured from 19:42 to 04:20 UTC (Lothon et al., 2014; Blay-Carreras et al., 2014) which are representative of the sunrise and sunset times during this period and in this area. An alternative method to select the study periods would be to consider the time when the sensible heat flux changes its sign instead of the sunset and sunrise; however, the first approach was followed for consistency with previous studies.

Two datasets with different sampling frequencies were used from Skinflow mast levels between $z_{2} \mathrm{~m}$ and $z_{88}$ : thermocouples $(1 \mathrm{~Hz})$ and sonic anemometers $(10 \mathrm{~Hz})$ (Table 1). The time span of the available measurements for the Skinflow mast levels starts on 19 June 2011 and finishes on 8 July 2011. For the statistical study of the behaviour of the turbulence strength relationship with the wind speed we set a temporal average of $5 \mathrm{~min}$ as done in Sun, 2011; Sun et al., 2012; Mahrt, 2014. We used this temporal average because reducing the averaging period, or using other methods, such as multi-resolution decomposition or wavelet, might potentially eliminate the contribution of non-turbulent mesoscale motions to the calculated turbulence quantities (Terradellas et al., 2005; Udina et al., 2013; Ferreres et al., 2013; Soler et al., 2014). However, to obtain a broad picture of the patterns, a constant averaging time of 5 min seemed sufficient. In addition, as stated by Mahrt (2017), in very stable conditions, variations in turbulent fluxes on timescales of a few minutes to tens of minutes are often associated with short periods of near-calm conditions where the turbulent fluxes are particularly small, and as a result their values are not very dependent on the averaging time. The high-frequency signal of the turbulence is used to calculate average statistics to show a broad picture of the patterns. However, when the aim is to show the temporal evolution of the turbulent variables in more detail, a small temporal average set with averages ranging between $10 \mathrm{~s}$ and $1 \mathrm{~min}$ is obtained. This high-frequency procedure aims to account for the turbulence intermittency within and between the different turbulent regimes defined in the HOST theory. In the atmospheric boundary layer (ABL), intermittency is basically found on the stable boundary layer (SBL) over land at night, especially under conditions of large static stability and strong vertical wind shear, when turbulence is sporadic, and characterized by bursts or episodes with periods of relatively weak or unmeasurable small fluctuations. In this paper we use the term "intermittency", to specifically describe a temporal variation of the turbulence intensity or turbulence strength, represented by the $V_{\mathrm{TKE}}$ value calculated at a fixed location, as in Sun et al. (2012). Reasons for increased turbulence are diverse and may include the intrusion of coherent structures such as gravity waves, density currents (Terradellas et al., 2005; Udina et al., 2013; Ferreres et al., 2013; Soler et al., 2014), and low-level jets (LLJs) (Mahrt, 1999; Newsom and Banta, 2003; Cuxart and Jiménez, 2007).

From the Valimev $60 \mathrm{~m}$ tower we used the measurements from the sonic anemometers located at the $z_{30 \mathrm{~m}}, z_{45 \mathrm{~m}}$, and $z 60 \mathrm{~m}$ levels, as shown in Table 1 . The dataset for this tower starts on 14 June 2011 for the $z_{30 \mathrm{~m}}$ and $z_{45 \mathrm{~m}}$ levels, and slightly later for the $z_{60 \mathrm{~m}}$ level, between 10:00 and 11:00 UTC on 15 June 2011, and finishes on 8 July 2011 for the three levels. The same data processing method used for the Skinflow mast levels measurements is applied to the Valimev levels, using temporal averages of $5 \mathrm{~min}$ in addition to averages ranging between $10 \mathrm{~s}$ and $1 \mathrm{~min}$.

We follow the corrections and filters indicated in Said et al. (2011a, b) and De Coster et al. (2011), where the postprocessing method applied to the BLLAST data is explained in detail (e.g. applying a planar-fit rotation to the wind direction dataset). Additionally, sonic measurements were not considered when anomalous $V_{\mathrm{TKE}}$ values were observed during rainfall periods.

We calculate several parameters in order to study the turbulence regime relationships. The first of these was the wind speed, $V$ :

$V=\sqrt{u^{2}+v^{2}}$,

where $u$ and $v$ are the horizontal wind components. The second was the turbulence intensity or turbulence strength, $V_{\text {TKE }}$ :

$V_{\mathrm{TKE}}=\sqrt{\frac{1}{2}\left(\sigma_{V}^{2}+\sigma_{w}^{2}\right)}$,

where $\sigma$ represents the standard deviation of the wind components, and $\sigma_{V}^{2}=\sigma_{u}^{2}+\sigma_{v}^{2}$ represents the potential virtual temperature:

$\theta_{v}=T_{v}+\Gamma_{\mathrm{d}} z$. 


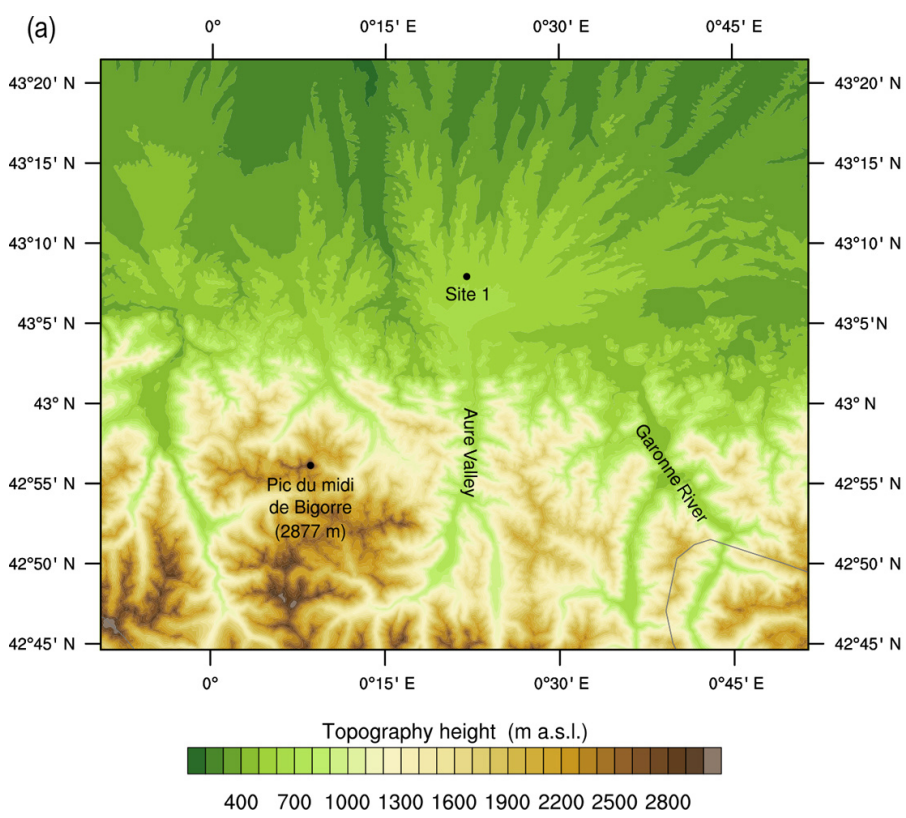

(b)

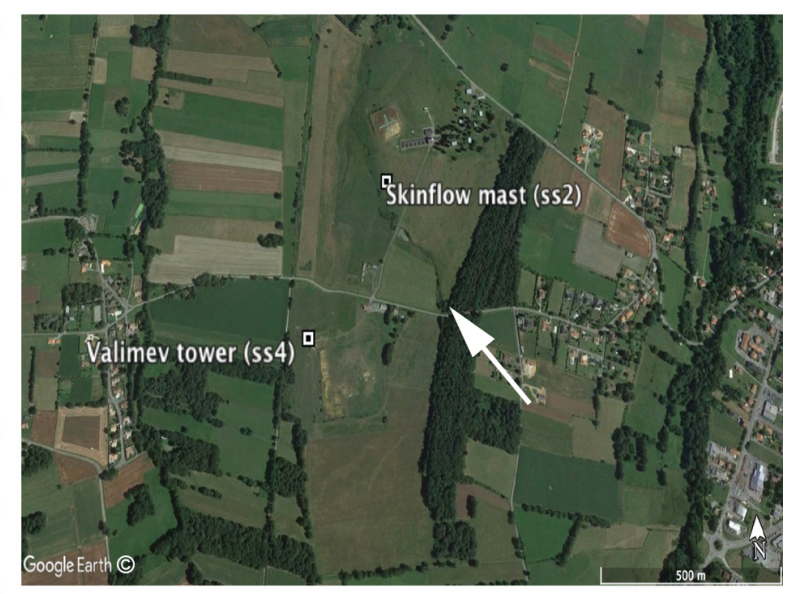

Figure 2. Location of the "Plateau de Lannemezan" and the surrounding area including (a) a topographical map of the surroundings of Site 1, where the BLLAST field campaign took place, showing the terrain elevation of the area, with the Pyrenees mountain range to its south, and the locations of the Aure Valley and the Garonne River. (b) A satellite view (from ( $)$ Google Earth) of Site 1 showing the location of the Skinflow mast at surface site 2 (ss2), the Valimev tower at surface site 4 (ss4), and a small gully south-east of the Skinflow mast (white arrow).

Table 1. Skinflow mast and Valimev tower sonic measurements from the BLLAST field campaign used in this study.

\begin{tabular}{|c|c|c|c|c|}
\hline $\begin{array}{l}\text { Level } \\
\text { name }\end{array}$ & $\begin{array}{r}\text { Height } \\
(\mathrm{m})\end{array}$ & $\begin{array}{r}\text { Measured } \\
\text { variables }\end{array}$ & Sensors & Data period \\
\hline$z_{2 \mathrm{~m}}$ & 2.23 & \multirow{7}{*}{$\begin{array}{c}T\left({ }^{\circ} \mathrm{C}\right) \\
(u, v, w) \\
\left(\mathrm{m} \mathrm{s}^{-1}\right)\end{array}$} & & \multirow{4}{*}{19 June-8 July 2011} \\
\hline$z 3 \mathrm{~m}$ & 3.23 & & Campbell type E thermocouple FW05 & \\
\hline $25 \mathrm{~m}$ & 5.27 & & Campbell CSAT3 3-D sonic anemometer & \\
\hline$z 8 \mathrm{~m}$ & 8.22 & & & \\
\hline$z_{30 \mathrm{~m}}$ & 29.4 & & Campbell CSAT3 3-D sonic anemometer & \multirow{2}{*}{14 June-8 July 2011} \\
\hline$z 45 \mathrm{~m}$ & 45.8 & & $\begin{array}{l}\text { Gill master pro } 3-\mathrm{D} \text { sonic anemometer, } \\
\text { wind vane }\end{array}$ & \\
\hline$z_{60 \mathrm{~m}}$ & 61.4 & & Campbell CSAT3 3-D sonic anemometer & 15 June-8 July 2011 \\
\hline
\end{tabular}

In the above equation $T_{v}$ is the virtual temperature at each height $z$, and $\Gamma_{\mathrm{d}}$ is the dry adiabatic lapse rate. Finally, we calculate the skewness of the vertical velocity fluctuations as follows: (Wyngaard, 2010):

$S_{w}=\frac{\overline{w^{\prime}(z)^{3}}}{\left(\overline{w^{\prime}(z)^{2}}\right)^{3 / 2}}$,

which gives us information about the vertical transport (upward or downward) of the vertical velocity variance.

Furthermore, when the relationship $V_{\mathrm{TKE}}$ vs. $V$ is graphically analysed we use the bin-average technique where we group the data into wind speed bins of $0.4 \mathrm{~m} \mathrm{~s}^{-1}$ starting at a wind speed of $0.1 \mathrm{~m} \mathrm{~s}^{-1}$. For each of these bins, the me- dian value with the corresponding error bars is displayed. These error bars represent the first and third quartiles instead of the actual standard deviation as a consequence of the skewed distribution of the turbulence points for each wind speed bin. This bin-averaged technique is also employed for the box plot analysis. In addition, we carried out an exhaustive analysis in order to exclude the measurements collected under strong precipitation conditions, during which sonic anemometers do not work properly. 


\section{Flow characterization during the BLLAST field campaign}

The objective of this paper is to study how the HOST theory behaves in an environment with complex terrain during the BLLAST field experiment in the nocturnal boundary layer. In the area, during night-time when thermally driven flows can be developed, a katabatic flow moving down from the mountain to the plain is established, via valley and downslope winds (Román-Cascón et al., 2015, 2019). As the HOST theory proposed by Sun et al. $(2012,2016)$ during the CASES99 campaign corresponds to nights with clear skies and intense radiative cooling, which allow for the development of local and mesoscale winds, we first select the nights that meet these conditions during the BLLAST campaign. This is carried out in a similar fashion to Lothon et al. (2014), who selected the intensive observation periods (IOPs) in BLLAST that focused on the diurnal and the late-afternoon transition boundary layer analysis. However, in this study, we consider night as an IOP, hereafter nIOP, which refers to period between 19:42 UTC of that IOP day and 04:20 UTC of the following day (Blay-Carreras et al., 2014). That is, the evening, night, and early morning following an IOP day, excluding any nocturnal period strongly influenced by larger-scale phenomena, such as a synoptic frontal system or mesoscale convective systems. In cases where the night-time period prior to the IOP shows the typical nocturnal flow cycle, we consider the early morning of the corresponding IOP, i.e. from 00:00 to 04:20 UTC. Following these criteria, Table 2 shows the nocturnal periods considered as nIOPs.

To characterize the wind flow regimes on the Plateau de Lannemezan for the nIOPs, the first step is to calculate the wind roses for each level of measurement, both for the Skinflow mast and the Valimev tower. Fig. 3 shows that $25 \%$ of the flows at the lower levels, $z_{3} \mathrm{~m}-z_{8} \mathrm{~m}$, come from the south-east quadrant, which correspond to shallow drainage flows (SDFs), formed after sunset due to local and very small slopes located in the foothills of the Pyrenees (RománCascón et al., 2015). These authors found that up to $4 \mathrm{~d}$ during the BLLAST campaign present SDFs after the near-calm period of the afternoon, exhibiting a wind maxima (around $1.5-2 \mathrm{~m} \mathrm{~s}^{-1}$ close to the surface) in the first $5 \mathrm{ma}$ a.g.l. At higher levels, $z_{30 \mathrm{~m}}-z_{60} \mathrm{~m}$, wind roses show a large fraction of winds coming from the south-east quadrant $(35 \%$ of the data), which are associated with the larger-scale mountainplain flows (MPFs). In this case the location of the maximum wind is higher, at $80 \mathrm{~m}$ as stated Román-Cascón et al. (2015), or between 50 and $200 \mathrm{~m}$ corresponding to the Aura Valley exit flow (Jiménez et al., 2019). To document the SDFs and the MPFs, we present an example shown in Román-Cascón et al. (2015) between noon on the 2 of July and the morning of the 3 July 2011, including nIOP09. The predominant wind direction during the central part of the day is from the north, corresponding to the uphill direction (Jimenez and Cuxart, 2014), with an average wind speed of $2 \mathrm{~m} \mathrm{~s}^{-1}$. Later that day, the 2 July, at 18:00 UTC, the wind turns to south-south-east, first at the lower levels, which correspond to drainage winds with lower velocities; then, $2 \mathrm{~h}$ later, at 20:00 UTC, the wind veers towards the south-east at all levels, increasing its velocity to $5 \mathrm{~m} \mathrm{~s}^{-1}$ associated with a mountain-plain flow. The presence of a gully south of the Skinflow mast (Fig. 2b) has a relevant effect on the wind (Fig. 3) due to the frequent formation of a shallow drainage flow under very stable conditions (Nauta, 2013; Soler et al., 2002). The night flow for those stable nights has an intermittent nature as it is generated by drainage flows, mountain-plain flows, and other mesoscale phenomena induced by the temperature gradients between the plains and the most northern mountain ranges of the Pyrenees located south of the site.

Figure 3 also shows that the Valimev tower presents a remarkable fraction ( $25 \%-30 \%$ of all data) of winds from the west and north-west; this can be closely connected to the fact that the wind is from the north-north-west during the central part of the day preceding nIOPs, corresponding to the uphill direction, but turns to the south-east $2 \mathrm{~h}$ after sunset, especially at the higher levels. As a consequence the north-west winds may prevail at high levels during nIOPs despite their anabatic origin.

Although the main focus of this paper is the study of the HOST theory for the SBL, we also aim to analyse the behaviour of such theory for non-nIOP conditions, and how the peculiarities of the Plateau de Lannemezan site affect its structure. Bearing this in mind we represent the wind rose for the whole night-time dataset from the same levels of both towers (Fig. 4). One of the most relevant results for the Skinflow tower is the increasing frequency of winds coming from the westerly sector when all data are considered, unlike in nIOPs where westerly winds are almost negligible. The reason for this may be the fact that winds from the west and west-north-west, linked to larger-scale synoptic (Barneoud et al., 2010) flow, are very frequent in this part of Europe, with additional channelizing to westerlies due to the mountain range south of the site. The same result is observed for the Valimev tower, although winds from the south-east sector become slightly less dominant. For both datasets, southeast is clearly predominant for the Skinflow tower heights vs. Valimev; this is because Skinflow tower has measurements at very low levels and, therefore, it is able to measure small-scale phenomena as SDFs which are generated by small-scale features such as local slopes.

As we have seen throughout the flow characterization, the presence of shallow drainage flows, mountain-plain flows, and the Aura Valley jet favours the formation of LLJ with maximum winds at different heights. In addition, taking into account the results of previous work carried out by Nilsson et al. (2016), who derived wind profiles during 10 IOP nights via the analysis of the Skinflow mast, showed that all of them, except one, displayed reverse wind gradient or nonmonotonic wind profile with a wind direction from about 120 to $180^{\circ}$. Therefore, we can argue that LLJs are a fre- 
Table 2. Night-time data (between 19:42 and 04:20 UTC) from the Skinflow mast and Valimev tower levels considered as IOP nights. The temporal series starts on 14 June for the first two levels for sonic anemometers from the Valimev tower, and on $15 \mathrm{June}$ for $z_{60 \mathrm{~m}}$; for the Skinflow data, the measurements began on 19 June.

\begin{tabular}{llll}
\hline nIOP & Corresponding night-time IOP & Date $(\mathrm{dd} / \mathrm{mm})$ & Levels \\
\hline nIOP00 & IOP00-IOP01 & $14 / 06-15 / 06$ & $z_{30 \mathrm{~m}}, z_{45 \mathrm{~m}}$ \\
nIOP01 & IOP02-IOP03 & $19 / 06-20 / 06$ & $z_{30 \mathrm{~m}}-z_{60 \mathrm{~m}}$ \\
nIOP02 & IOP03 & $20 / 06(19: 42-23: 59$ UTC) & $z_{3 \mathrm{~m}}-z_{60 \mathrm{~m}}$ \\
nIOP03 & IOP04-IOP05 & $24 / 06-25 / 06$ & $z_{3 \mathrm{~m}}-z_{60 \mathrm{~m}}$ \\
nIOP04 & IOP05-IOP06 & $25 / 06-26 / 06$ & $z_{3 \mathrm{~m}}-z_{60 \mathrm{~m}}$ \\
nIOP05 & IOP06-IOP07 & $26 / 06-27 / 06$ & $z_{3 \mathrm{~m}}-z_{60 \mathrm{~m}}$ \\
nIOP06 & IOP07 & $27 / 06(19: 42-21: 00$ UTC) & $z_{3 \mathrm{~m}}-z_{60 \mathrm{~m}}$ \\
nIOP07 & IOP08-IOP09 & $30 / 06-01 / 07$ & $z_{3 \mathrm{~m}}-z_{60 \mathrm{~m}}$ \\
nIOP08 & IOP09-IOP10 & $01 / 07-02 / 07$ & $z_{3 \mathrm{~m}}-z_{60 \mathrm{~m}}$ \\
nIOP09 & IOP10-03/07 & $02 / 07-03 / 07$ & $z_{3 \mathrm{~m}}-z_{60 \mathrm{~m}}$ \\
nIOP10 & IOP11 & $05 / 07(00: 00-04: 20$ UTC) & $z_{3 \mathrm{~m}}-z_{60 \mathrm{~m}}$ \\
\hline
\end{tabular}
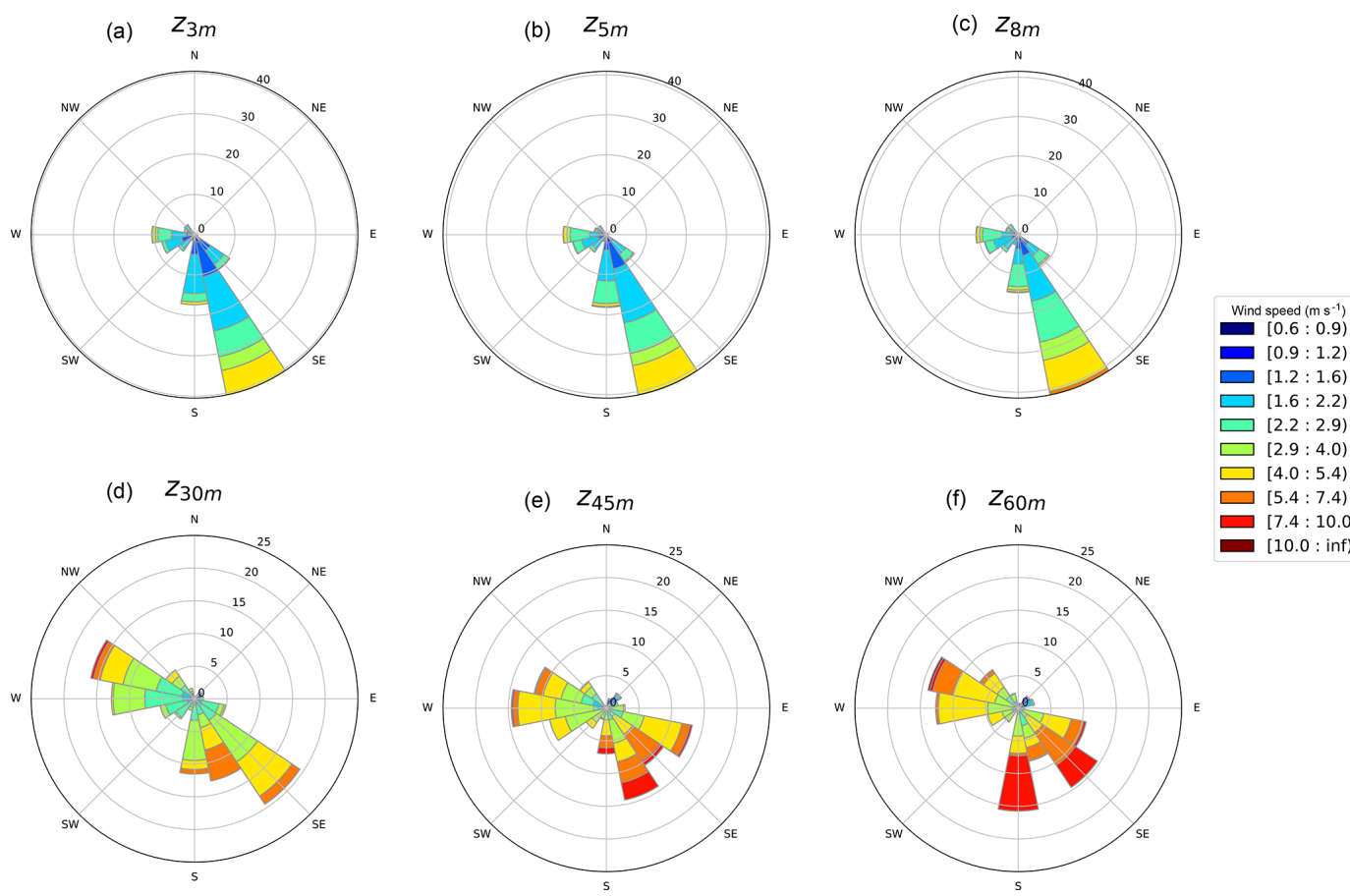
$\square[2.9: 4.0)$ $[4.0: 5.4)$ $[5.4: 7.4)$ $[7.4: 10.0)$

Figure 3. Night-time IOP (nIOP) wind roses for each level of the Skinflow mast (a-c) and the Valimev tower (d-f) during the BLLAST field campaign. Circles represent $10 \%$ frequency increments for the Skinflow mast levels and $5 \%$ frequency increments for the Valimev tower levels.

quent phenomenon during the BLLAST campaign. An exhaustive study regarding the relation between LLJs and turbulent regimes is outside of the scope of this paper. However, following Sun et al. (2012) the two following possibilities can be considered:

a. The maximum wind of a LLJ is lower than the HOST threshold for its height above the ground, but the local shear below the LLJ is not negligible. Therefore, moderate turbulence can be generated, diffusing downwards, especially when the vertical temperature gradient de- creases with height. This situation leads to turbulence regime 3 .

b. The maximum wind of a LLJ is greater than the HOST threshold for its height above the ground. In this case, regime 2 occurs.

In this way, in addition to other processes, the occurrence of the different regimes can be linked to the presence of LLJs.

After having classified and illustrated the flow circulation from the dataset, we analyse the turbulence regimes from two 

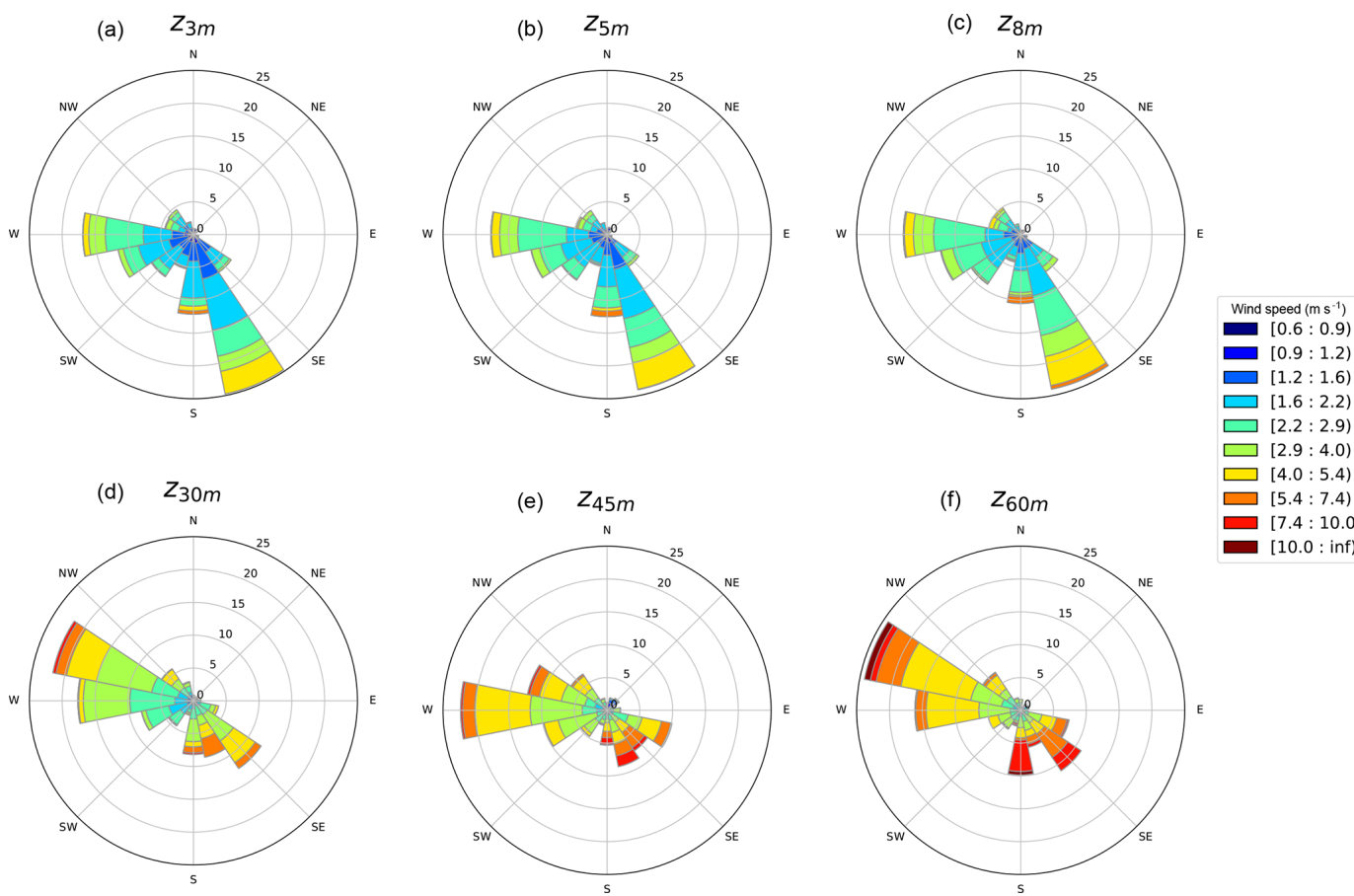
$[2.9: 4.0)$ $[4.0: 5.4)$ $[5.4: 7.4)$ $[7.4: 10.0)$

Figure 4. Night-time whole dataset wind roses for each level of the Skinflow mast (a-c) and the Valimev tower (d-f) during the BLLAST field campaign. Circles represent $5 \%$ frequency increments.

different perspectives: using only nIOP data (Sect. 4) and using the whole BLLAST dataset (Sect. 5).

\section{Turbulence regime analysis: nIOPs}

In this section we investigate the turbulence regimes using the data obtained from the so-called nIOPs in order to study the generality of the HOST pattern (Sun et al., 2012). We explore the dependence of the night-time turbulence intensity, $V_{\text {TKE}}$, on the horizontal wind speed $V$ for each of the observational levels. We also analyse the $V_{\text {TKE }}$ vs. $V$ relationship dependence on the thermal stratification via bulk virtual potential temperature differences between the Skinflow mast levels.

Figure 5a shows the relationship between $V_{\mathrm{TKE}}$ and $V$, where the wind speed threshold is marked for every level (see triangles in Fig. 5a). The turbulence intensity relationships with $V$ for the nIOPs have a similar hockey-stick shape to the one obtained by Sun et al. $(2012,2016)$ using data from CASES-99. As described schematically in Fig. 1, Fig. 5a shows that for a given height, below a wind speed threshold, $V_{\mathrm{T}}$, the turbulence intensity does not depend on the wind speed with no actual increase of $V_{\text {TKE }}$ (regime 1). On the contrary, above a given $V_{\mathrm{T}}, V_{\mathrm{TKE}}$ increases much more strongly than for lower wind speeds (regime 2). Table 3 shows the values of the wind speed thresholds obtained for the BLLAST field campaign during nIOPs. As observed by Sun et al. (2012) and Bonin et al. (2015), the wind speed threshold,
$V_{\mathrm{T}}$, (Table 3) also increases logarithmically with height at the BLLAST site during the nIOPs; the $r^{2}$ correlation between the logarithmic height and the wind speed is around 0.92 . The threshold value marks a change in the slope of the turbulence intensity relationship. Therefore, we consider that the regime changes to regime 2 , when the slope has increased by at least two times the value of the slope of regime 1. The higher the layer, i.e. the deeper the stratus below $z$, the greater the value of $V$ required for the layer to become neutral. Therefore, the $V_{\mathrm{T}}$ increases with height because larger shear production is needed to compensate for the inhibiting effect that near-surface stable stratification has on the TKE. The $V_{\mathrm{T}}$ values for nIOPs in BLLAST are lower than those obtained by Sun et al. (2012) for CASES-99 and the bulk shear $\left(V_{\mathrm{T}} / z\right)$ is weaker as well (Fig. 5b). This can be explained by the effect of a larger roughness length in the BLLAST site, associated with the mountainous terrain south of the site. The greater the roughness length, the smaller the $V_{\mathrm{T}}$, which means that weaker wind is necessary to achieve regime 2 , as also seen by Mahrt et al. (2013).

It is also noticeable that the slope for the regime 2 for all of the levels is quite similar, which indicates that, as expected, once the layer is neutral, the relationship between the turbulence intensity and the wind speed tends to be independent of the layer depth. Although the three turbulent regimes of the HOST pattern are visible at all levels, at the highest level, $z_{60 \mathrm{~m}}$, regime 2 does not seem to behave as expected for the highest wind speed values, showing a decrease in the turbu- 
Table 3. Wind speed thresholds $V_{\mathrm{T}}$ for the Skinflow mast and Valimev tower levels for the BLLAST field campaign.

\begin{tabular}{rrrrrrr}
\hline & $z_{3 \mathrm{~m}}$ & $z_{5 \mathrm{~m}}$ & $z_{8 \mathrm{~m}}$ & $z_{30 \mathrm{~m}}$ & $z_{45 \mathrm{~m}}$ & $z_{60 \mathrm{~m}}$ \\
\hline$V_{\mathrm{T}}\left(\mathrm{m} \mathrm{s}^{-1}\right)$ & 1.3 & 1.7 & 2.1 & 3.7 & 6.1 & 6.9 \\
\hline
\end{tabular}

lence intensity as the $V$ increases. This is due to the small amount of data for these wind speed bins; therefore, no statistical conclusion can be drawn from these results.

The relationships of $\sigma_{V}$ and $\sigma_{W}$ with $V$ (not shown) also present the HOST dependence seen for $V_{\mathrm{TKE}}$. However, the turbulence values are generally smaller for $\sigma_{W}$ with a smaller increase of the vertical variance with increasing $V$ in regime 2 due to the ground impingement, as found in Sun et al. (2012).

As turbulent mixing is influenced by the vertical temperature gradients, we now consider the effect of stratification on the turbulence relationship. We only proceed for the Skinflow mast because the separation of the measurements levels in the Valimev tower are too deep to calculate the stratification based on the bulk potential temperature difference, $\Delta \bar{\theta}_{v}$ (Sun et al., 2016). Herein $\Delta \bar{\theta}_{v}$ is defined as $\Delta \bar{\theta}_{v}=\bar{\theta}_{v}(z)-\bar{\theta}_{v_{z_{0}}}$, where $\bar{\theta}_{v_{0}}$ is the virtual potential temperature of reference at $z_{2} \mathrm{~m}$, and $\bar{\theta}_{v}(z)$ is the virtual potential temperature at each height $z$. An alternative approach to calculate the stratification conditions would be to use the thermal gradient instead. However, throughout the paper we have considered the bulk potential temperature difference method described in Sun et al. (2016), which also provides good results and allows for a more consistent comparison within the HOckey-Stick theory framework.

In Fig. 6 we observe that for wind speeds greater than the threshold, $V>V_{\mathrm{T}}$, the shear is strong enough to generate eddies with scale $z$, leading to a neutrally stratified boundary layer with a potential vertical temperature difference close to zero (green line). At all levels (Fig. 6a, b, c) for wind speeds below the threshold, the stratification of the night-time boundary layer becomes stable, so there is a shallow mixing layer with a depth determined by $\delta z<z$ (Sun et al., 2012). Therefore, turbulent eddies do not reach the surface and cold air is accumulated near the surface, resulting in layers with values of $\Delta \bar{\theta}_{v}>0.5 \mathrm{~K}$. However, in Fig. 6 we observe situations that deviate from those described above. For example, in regime 1 , for very stable situations $\left(\Delta \bar{\theta}_{v}>0.5 \mathrm{~K}\right)$, intermittent turbulence between regimes 1 and 2 , and between regimes 1 and 3, can occur. Note that these transitions increase the turbulence, giving rise to temperature variations and mixing that would result in a nearneutral or even unstable regime (see green and red lines in Fig. 6).

For $V>V_{\mathrm{T}}$ the turbulent mixing processes tend to decrease the variability of $\Delta \bar{\theta}_{v}$ (Sun et al., 2016) and the strati- fication becomes near-neutral. As is expected, for $V<V_{\mathrm{T}}$, the magnitude of the turbulence intensity, $V_{\mathrm{TKE}}$, increases with decreasing values of $\Delta \bar{\theta}_{v}$, as the relevance of the TPE decreases with instability (Zilitinkevich et al., 2007; Sun et al., 2016). Another important point to consider is the thickness of the layer, as $\Delta \bar{\theta}_{v}$ represents a vertically integrated virtual potential temperature difference; thus, $\Delta \bar{\theta}_{v}$ will increase when the height of the level increases (Fig. 6a, b, c). Therefore, due to the proximity between the $z_{3} \mathrm{~m}$ and $z_{22 \mathrm{~m}}$ levels most of the points fall into the stable-neutral stratification $0 \mathrm{~K}<\Delta \bar{\theta}_{v}<0.5 \mathrm{~K}$, which explains the predominance of the green line in Fig. $6 \mathrm{a}$. For the $z_{5 \mathrm{~m}}$ and $z_{8 \mathrm{~m}}$ levels, the number of bins with larger values of $\Delta \bar{\theta}_{v}$ increases as a consequence of being further up from the reference level.

\section{Turbulence regime analysis: whole BLLAST dataset}

Herein we aim to explore how well the HOST behaves when we use the whole night-time dataset from the BLLAST field campaign without any restriction. To achieve this objective, we carried out an analysis similar to the one outlined in Sect. 4; we first analysed the turbulence relationship, then performed a deeper analysis using box plots for each measurement level, and finally examined turbulence relationships with the thermal stratification. Therefore, the first step was to analyse the differences between all of the night-time data wind roses (Fig. 4) and those corresponding to nIOPs (Fig. 3). As we have seen in Sect. 3 the most remarkable feature is the high frequency of the western flows when the whole nocturnal dataset is considered. Taking into account that many storms and frontal systems were from this direction (Barneoud et al., 2010), the analysis is carried out by splitting the data between two sets of wind directions: the first group includes winds coming from directions ranging from 235 to $45^{\circ}$, referred as NWs, including the southwest to west, northwest, north, and northeast directions; the second group includes the remaining directions, from 45 to $235^{\circ}$ referred as SEs, including northeast to east, southeast, south, and southwest, which are mostly due to the local topographic effects (Sect. 3).

\subsection{Turbulence relationships}

As in Sect. 4, we analyse the turbulence intensity relationships, but herein we focus on the whole night-time dataset without differentiating the fair-weather nights from the nonfair-weather nights. The analysis is carried out by splitting the data into two main directions, flows coming from the NWs and the SEs directions (Fig. 7). For the NWs the relationship between the $V_{\text {TKE }}$ and $V$ is linear, so the HOST pattern is not observed (Fig. 7a). Contrary to this, for the SEs the $V_{\text {TKE }}$ vs. $V$ does resemble a hockey stick; we can also distinguish a $V_{\mathrm{T}}$ for each height (Fig. 7b), which are similar to those found for the nIOPs but not equal, as the 

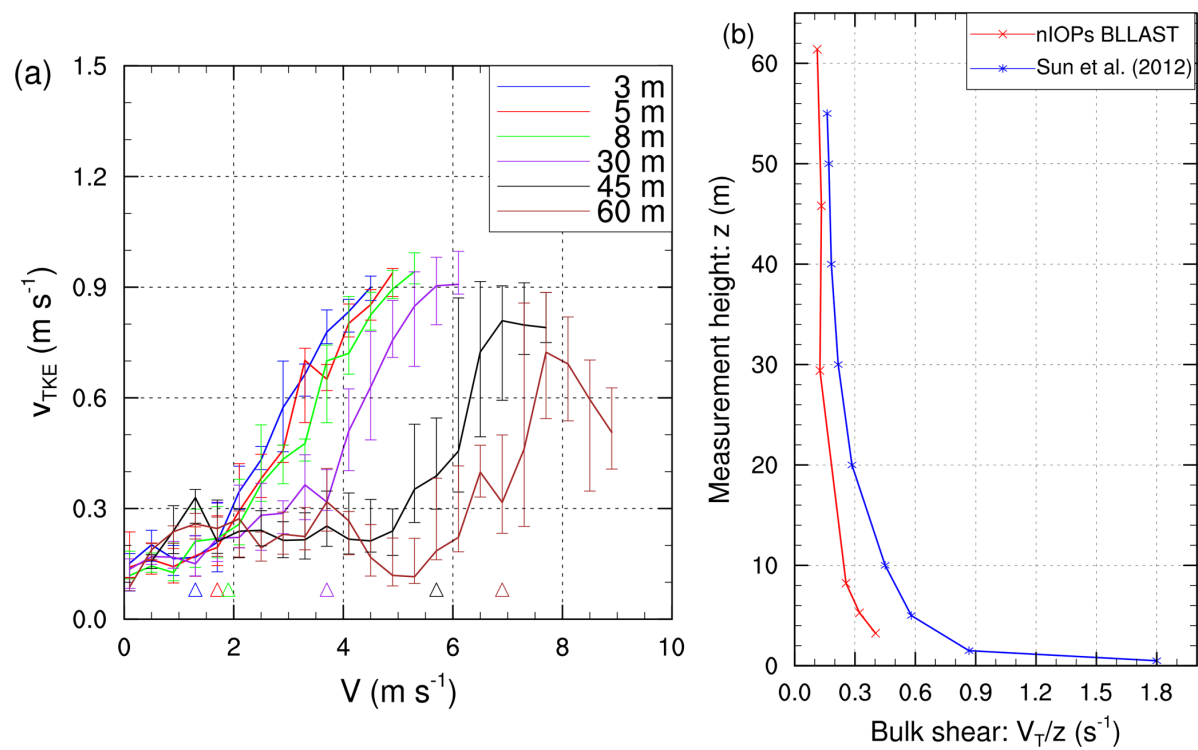

Figure 5. (a) Relationship between the bin-averaged turbulence intensity $V_{\text {TKE }}$ and the wind speed $V$ for the nIOPs of the BLLAST campaign. The lines join the median value of each $V$ bin $\left(0.4 \mathrm{~m} \mathrm{~s}^{-1}\right.$ bins) for each level of measurement. The lower and upper ends of the vertical lines of each bin mark the first and third quartiles, respectively. The wind speed threshold $V_{\mathrm{T}}$ is marked using a different-coloured triangle for each level. (b) Bulk shear variation with height obtained using BLLAST nIOPs data (red line) compared with CASES99 data reported by Sun et al. (2012; blue line).
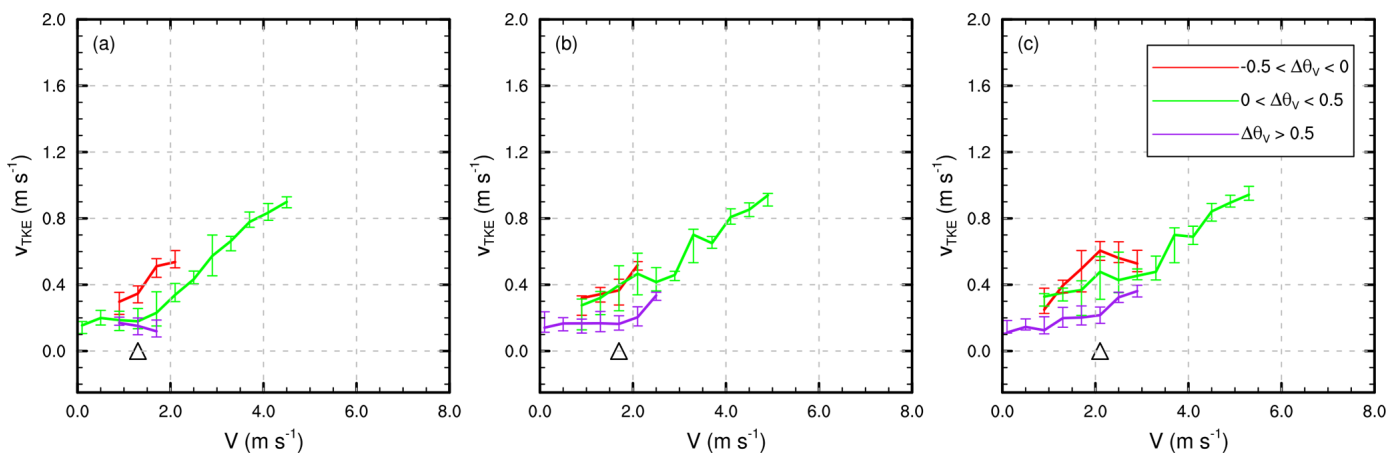

Figure 6. Relationship between the bin-averaged turbulence strength $V_{\mathrm{TKE}}$ and the wind speed $V$ during the BLLAST campaign nIOPs as a function of potential temperature difference intervals, defined as, $\Delta \bar{\theta}_{v}=\bar{\theta}_{v}(z)-\bar{\theta} v_{z_{0}}$, where $\bar{\theta} v_{z_{0}}$ is the virtual potential temperature of reference at $2 \mathrm{~m}$ a.g.l., and $\bar{\theta}_{v}(z)$ is the virtual potential temperature at each height $z:$ (a) $z_{3 \mathrm{~m}}$, (b) $z_{55 \mathrm{~m}}$, and (c) $z_{8 \mathrm{~m}}$. The wind speed threshold $V_{\mathrm{T}}$ is marked using a black triangle for each height (a) $z_{3 \mathrm{~m}}$, (b) $z_{5 \mathrm{~m}}$, and (c) $z_{8 \mathrm{~m}}$.

dataset herein includes all of the night-time data. In fact, most of the SEs situations correspond to nIOPs (between $63 \%$ and $70 \%$ of them), so the hockey-stick shape reproduced in Fig. $7 \mathrm{~b}$ is very similar to that shown in Fig. 5. Indeed, this plot mostly corresponds to fair-weather nights when stably stratified and near-neutral stratifications occurred and both regimes (regimes 1 and 2) could be distinguished. In contrast, situations corresponding to NWs are tied to frontal systems, cloud skies, or cyclonic situations, which substantially modify the boundary layer ideal structure. Specifically, in these situations the surface may not have been warmed much during the day so nocturnal cooling effects were much more limited; thus, the low-wind speed region of the HOST pattern is rarely reached, and regime 1 is not well illustrated in the $V_{\text {TKE }}$ vs. $V$ relationship. For the NWs wind directions, the turbulence seems to be mainly driven by bulk shear, and the HOST turbulence intensity relationship may not be valid in those cases.

\subsection{Box plot analysis}

In order to further understand the turbulence behaviour, we illustrate the relationship between $V_{\mathrm{TKE}}$ and $V$ using the box plots for each of the measured levels and wind speed bins as described in Sect. 2. To ensure the representativeness of the box plots a minimum of six measurements for each bin 

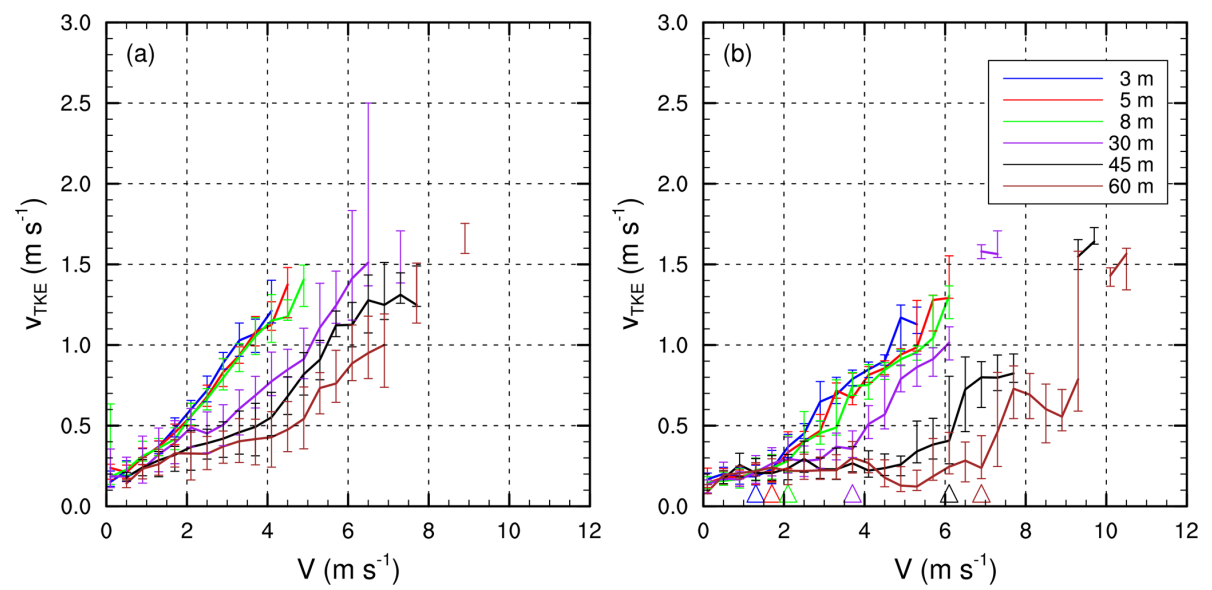

Figure 7. Relationships between the bin-averaged turbulence strength $V_{\mathrm{TKE}}$ and the wind speed $V$ for the whole BLLAST field campaign for the main directions considered: (a) wind coming from 225 to $45^{\circ}$ (included), referred to as NWs, and (b) winds coming from 45 to $225^{\circ}$ (included), referred to as SEs. Each line represents the median within each $0.4 \mathrm{~m} \mathrm{~s}^{-1} \mathrm{~V}$ bin. The vertical lines represent the deviation for each $V$ bin with the low limit corresponding to Q1 and the upper limit to Q3. The threshold wind speed $V_{\mathrm{T}}$ is marked using a triangle with the height colours shown in the legend of (b).

is required. The method is a simple form to represent several simple statistics, such as the minimum and the maximum, the lower and upper quartiles, and the median in a visual display. The amplitude of the box, i.e. the inter-quartile range (IQR), depends on the dispersion of the points within the bin, if $V_{\mathrm{TKE}}$ varies considerably for a given value of $V$, the box will be larger. The whisker lengths are proportional to the dispersion of $V_{\text {TKE }}$.

As can be seen in Figs. 8, 9, and A1 the $V_{\text {TKE }}$ data distribution for each bin is not Gaussian and the upper whiskers are generally longer than the lower ones. This skewness is due to the absence of negative values and the fact that the turbulence intensity can be enhanced due to the presence of coherent structures, typical in regime 1 and transitioning to regime 3, i.e. for $V<V_{\mathrm{TKE}}$. The quantity of outliers indicates the presence of turbulent events leading to an increase in the turbulent intensity which differs greatly from the value expected for a given range of $V$. This situation corresponds to regime 3 characterized by intermittent turbulence phenomena, which is typical for clear and calm nights.

The number of outliers within regime 3 is higher for wind speeds below the threshold, as the variability of the turbulence is higher. Instead, the strong wind associated with neutral stratification tends to suppress the occurrence of regime 3. It can be noted that for wind speeds closer to the threshold the scatter increases (Figs. 8d, e, f, 9d, e, f), which is due to the bin-averaged technique and the fact that the turbulence intensity increases more quickly around this velocity. The increase in scattering is observed in the IQR values, i.e. the larger length of the boxes, and in the greater amount of outliers.

We further examine the turbulence relationships separately for lower (Skinflow mast) and higher levels (Valimev tower).
Thereafter we apply two conditions to distinguish why the turbulence intensity is higher than expected. These points are outliers which have a very high $V_{\text {TKE }}$ value, due to a quick change of the horizontal wind speed, $\sim 1 \mathrm{~m} \mathrm{~s}^{-1}$, between consecutive measurements (green crosses in Figs. 8 and 9) or a shift in the wind direction of more than $\sim 75^{\circ}$ between consecutive measurements (red asterisks in Figs. 8 and 9). These points represent enhanced turbulence intensity for a certain period (temporal average of $5 \mathrm{~min}$ ) due to either wind speed shear or directional shear (Mahrt et al., 2013). Black dots are outliers not attributed to any of these shears, typical of regime 3, associated with top-down turbulent events.

In the following subsections we discuss the box plots for the Skinflow mast levels that are represented in Fig. 8 and the box plots for the Valimev tower levels in Fig. 9.

\subsubsection{Skinflow mast levels}

As seen in Sect. 5.1, it is not expected that the relationship between $V_{\mathrm{TKE}}$ and $V$ for the NWs directions will behave as the HOST predicts (Fig. 7); hence, for these directions, a similar behaviour is seen for the $z_{3 \mathrm{~m}}$ (Fig. 8a), $z_{5 \mathrm{~m}}$ (Fig. 8b), and $z_{8 \mathrm{~m}}$ (Fig. 8c) levels, where the turbulence strength increases near-linearly with $V$, and the first regime is not present. The whisker length is small except for lower and higher wind speeds at $z_{8 \mathrm{~m}}$; therefore, the dispersion is low and most of the points are close to the median, so that the resulting relationship is fairly linear.

For the thermally driven flows, the HOST pattern is clearly identified following both the whiskers and the median values of Fig. 8d, e, and f. There is also a large number of enhanced turbulence points at all levels triggered mostly by wind speed and directional shear. In addition, for regime 1, there is a large number of black outliers close to the whiskers that can 

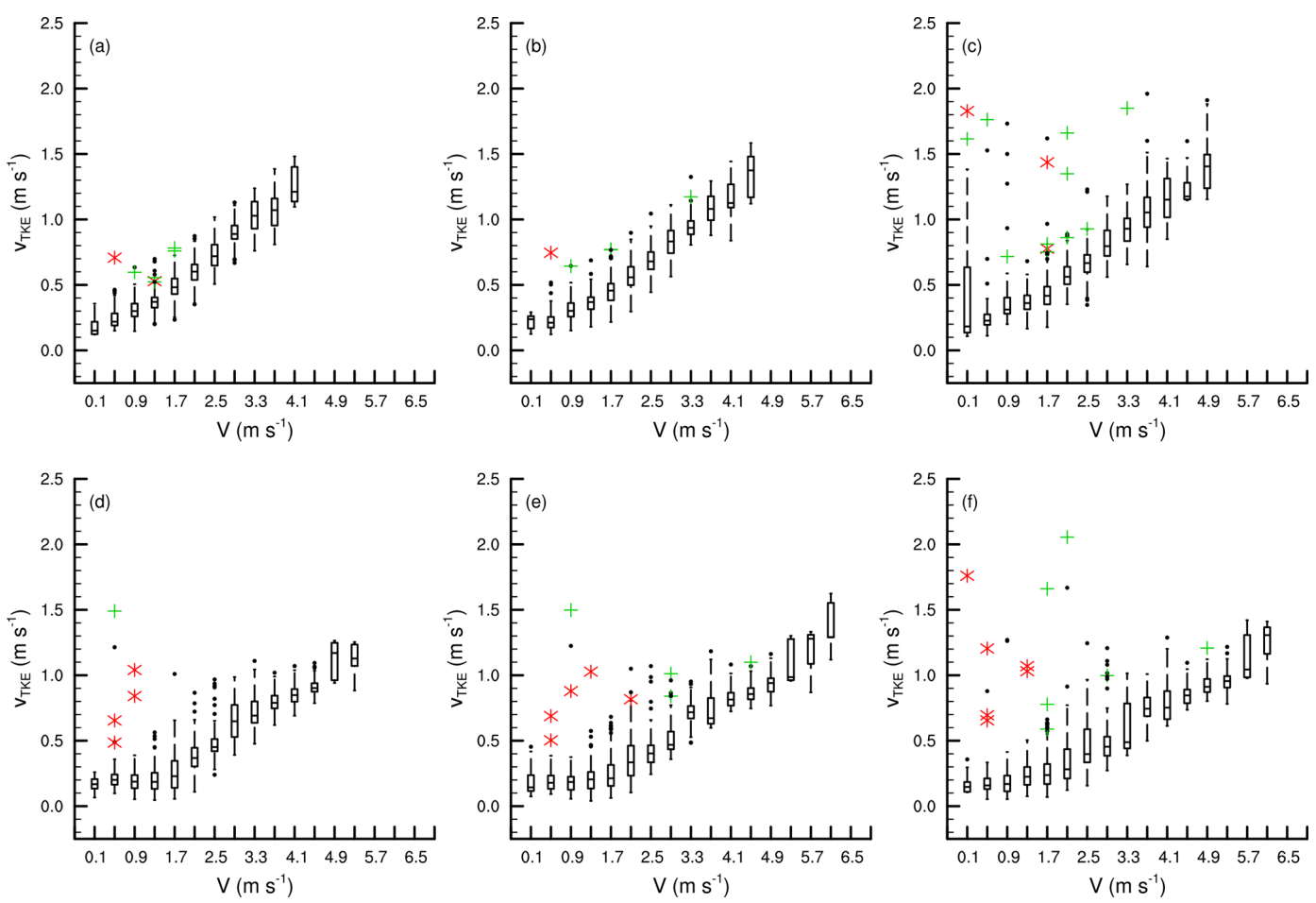

Figure 8. Box plots of the relationship between the bin-averaged turbulence strength $V_{\mathrm{TKE}}$ and the wind speed $V$ for the Skinflow nighttime dataset for the whole BLLAST field campaign. The maximum whisker length is proportional to 1.5 times the third and first quartile difference, or inter-quartile range (1.5 $\cdot \mathrm{IQR})$. Panels (a-c) correspond to the NWs direction range for (a) NWs at $z_{3 \mathrm{~m}}$, (b) $\mathrm{NWs}$ at $z_{5 \mathrm{~m}}$, and (c) NWs at $z_{8 \mathrm{~m}}$, and panels (d-e) correspond to the SEs directions, (d) SEs at $z_{3 \mathrm{~m}}$, (e) SEs at $z_{5 \mathrm{~m}}$, and (f) SEs at $z_{8} \mathrm{~m}$. The outliers represent a turbulence enhancement due to a quick variation of the wind speed (greater than $1 \mathrm{~m} \mathrm{~s}^{-1}$; green crosses), due to a sharp change in the wind direction (greater than $75^{\circ}$; red asterisks), or due to any other factor (black dots).

be related to regime 3 , as top-down turbulent events associated with orographic effects are expected to occur from this direction. The IQR range tends to be small except for higher wind speeds, and the whiskers tend to be relatively close to the median. However, for wind speeds close to $V_{\mathrm{T}}$ the boxes and whiskers are longer, as the corresponding bin-averaged velocity includes turbulence intensities corresponding to the two different turbulence regimes ( 1 and 2), with the later having a greater $V_{\text {TKE }}$ than the former.

When comparing the SEs box plots (Fig. 8d, e, f) with the nIOP box plots (Fig. A1a, b, c in the Appendix), the number of outliers and the whisker length is considerably greater than for the nIOP situations. This large number of outliers present in the SEs directions (Fig. 8d, e, f) is a remarkable difference from what was observed in Sun et al. (2012) and in the nIOP box plot analysis (Fig. A1), where little dispersion was found for each $V$ bin. This increase in the dispersion of the turbulence intensity values for a fixed $V$ may be associated with the topographical influence and especially with the weather conditions (synoptic scale), revealing an increase in the occurrence of non-stationary flows. While CASES-99 was located in a nearly flat terrain, BLLAST is a highly topographically influenced area, where the presence of storms and low pressure systems that affect the region is also common.

\subsubsection{Valimev tower levels}

For the Valimev tower we carried out the same study as before, also taking the same main wind directions into account (NWs and SEs). One of the main results is related to both the IQR range and the whiskers length: for NWs and SEs, they both increase with the height of the measurement, indicating a wide variety of turbulence intensity cases (Fig. 9).

Similarly to the Skinflow levels, the HOST pattern is not observed for the NWs directions, whereas the turbulence intensity does follow the HOST pattern for the SEs. For regime 1 in the SEs (Fig. 9d, e, f), even though the boxes are small, there is a great number of outliers, and many of them are very close to the whiskers which would correspond to regime 3 . Turbulence enhancement due to wind speed shear dominates over wind directional shear at these levels. Many other outliers (black dots) close to the whiskers in regime 1 are identified as top-down turbulent events (e.g. Kelvin-Helmholtz instabilities, gravity waves, or other intermittent turbulence events).

Similar to what was observed for the Skinflow mast levels, the comparison between the SEs box plots (Fig. 9d, e, f) and the nIOPs box plots (Fig. A1d, e, $f$ in the Appendix), the Valimev tower levels show a greater number of outliers and a 

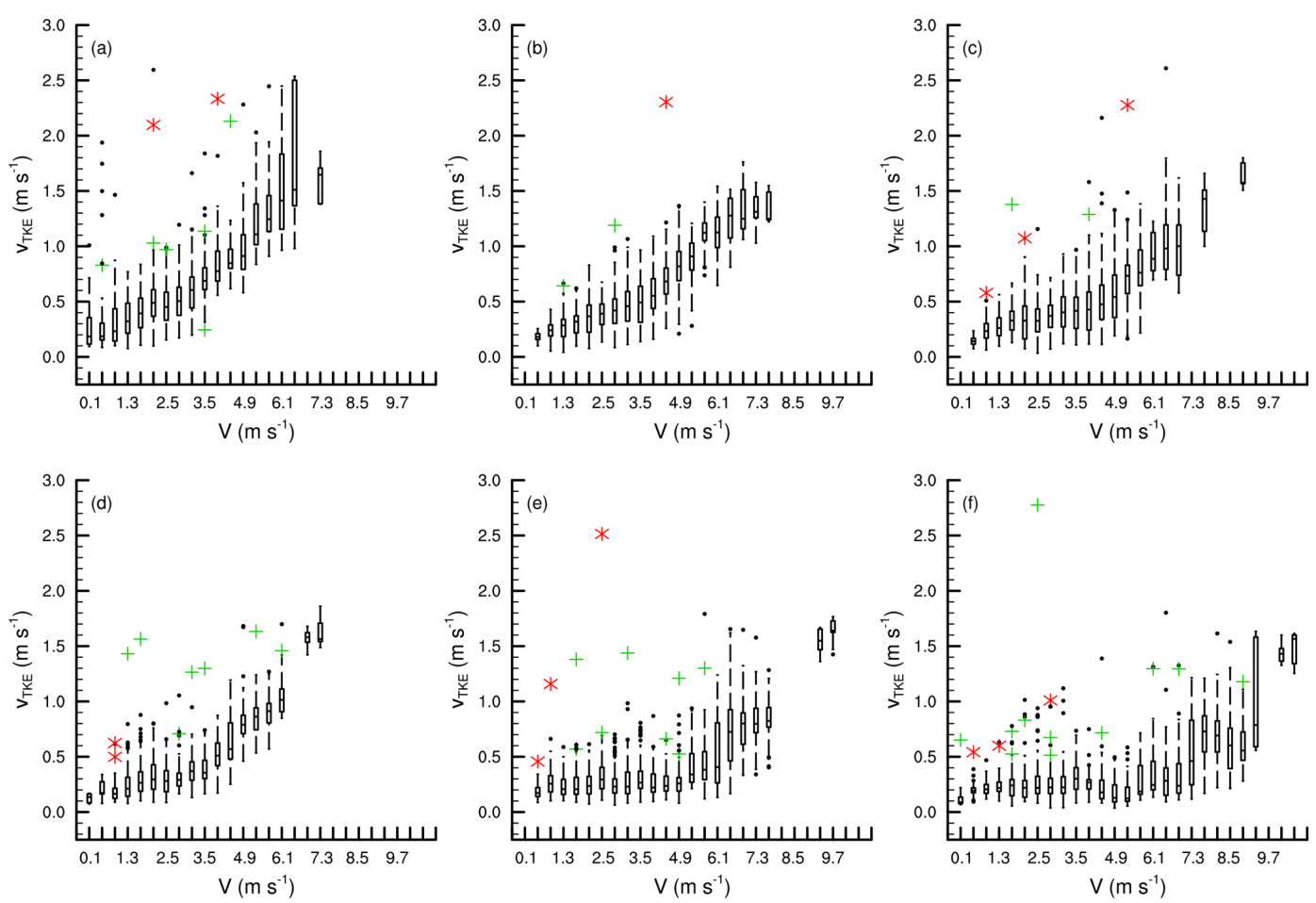

Figure 9. As in Fig. 8 but for the Valimev dataset for the whole BLLAST field campaign. Panels (a-c) correspond to the NWs direction range for (a) NWs at $z_{30 \mathrm{~m}}$, (b) NWs at $z_{45 \mathrm{~m}}$, and (c) NWs at $z_{60 \mathrm{~m}}$, and panels (d-f) correspond to the SEs directions for (d) SEs at $z_{30 \mathrm{~m}}$, (e) SEs at $z_{45 \mathrm{~m}}$, and (f) SEs at $z_{60 \mathrm{~m}}$.

larger whisker length for the SEs box plots, which may also be linked to the topographical influence and the meteorological synoptic conditions.

Overall, due to the lack of data for high wind speeds, some box plots are not available; however, the regime 2 pattern can be observed. The wind speed bins with values close to the $V_{\mathrm{T}}$ show greater dispersion (Figs. 8 and A1) than the rest, indicating the inherent uncertainty in determining the observed $V_{\mathrm{T}}$ value.

\subsection{Turbulence regimes and thermal stratification}

To further understand the HOST pattern, we explore the effect of stratification on the turbulence relationship for the whole BLLAST dataset, as previously carried out in Sect. 4 for the nIOPs. We also separate the data depending on the two wind directions considered, NWs (Fig. 10a) and SEs (Fig. 10b). We only use data from the Skinflow mast, and because the results for the different levels $\left(z_{33}, z_{5 \mathrm{~m}}\right.$, and $\left.z_{8 \mathrm{~m}}\right)$ are very similar, we only undertake the analysis and the discussion for the $z 5 \mathrm{~m}$ level.

For the NWs flows (Fig. 10a), turbulent mixing leads to a neutral stratification (red and green lines) and also to unstable stratification (turquoise lines), indicating thermal instability in the flow. Stable stratification (purple line) only appears to be associated with very low velocities and with relatively large $V_{\mathrm{TKE}}$ values. Therefore, the linear turbulence relationship is independent of the temperature gradients. Turbulence is driven by bulk shear; therefore, the flow incoming from this direction is such that it carries turbulence even for lower wind speeds, i.e. large eddies, which produce similar $V_{\mathrm{TKE}}$ independently of the temperature gradient and of the stratification of the nocturnal ABL.

For the thermally driven flows (Fig. 10b) the behaviour of the turbulence intensity vs. the wind speed depending on $\Delta \bar{\theta}_{v}$ is analogous to that found for the nIOPs (Sect. 4). Regime 1 is mostly associated with strong positive temperature gradients (purple lines) while near-neutral (green line) and unstable (red line) stratification is characteristic of regimes 2 and 3 . Indeed, the characteristic events of regime 3, can overturn the typical nocturnal positive temperature gradients.

\section{Transition between regimes and turbulence intermittency}

Associated with the transition among the three turbulence regimes, Sun et al. (2012) defined three turbulent intermittency categories: A, B, and C (Fig. 1). Category A corresponds to the transition between regime 1 and regime 2 , and vice versa, the wind speed oscillates between both regimes generating intermittent turbulence. Category B corresponds to the enhancement of turbulence within the regime 1 caused by atmospheric disturbances such as internal gravity waves, 

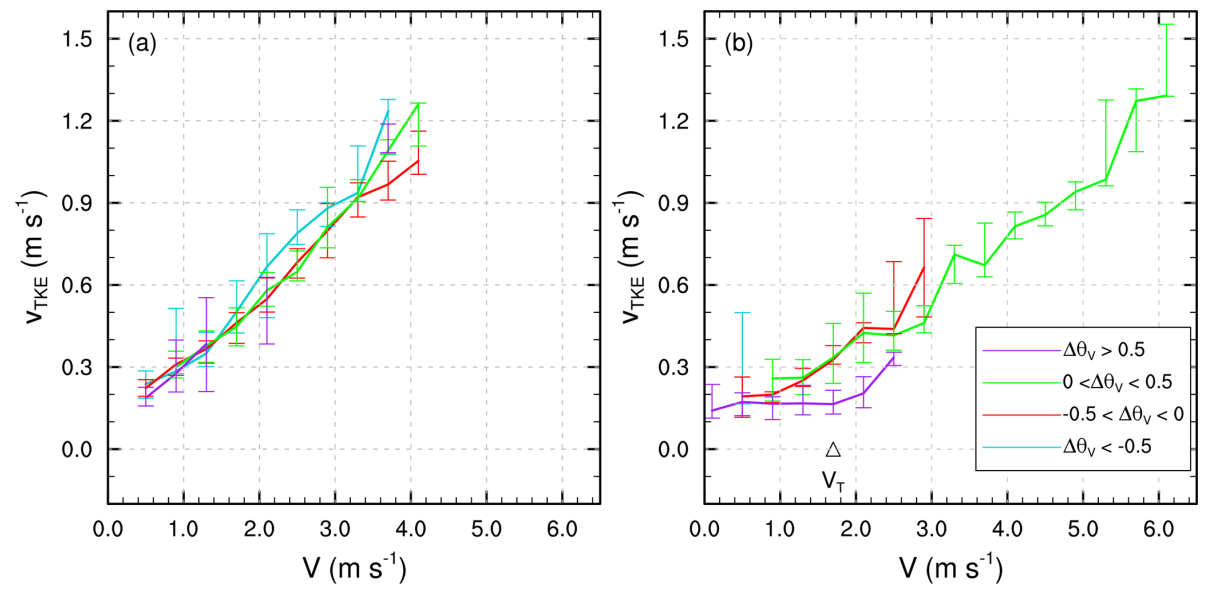

Figure 10. Relationship between the bin-averaged turbulence strength $V_{\mathrm{TKE}}$ and the wind speed $V$ during the BLLAST campaign nIOPs as a function of potential temperature difference intervals, defined as, $\Delta \bar{\theta}_{v}=\bar{\theta}_{v}(z)-\bar{\theta}_{v_{z_{0}}}$, where $\bar{\theta}_{v_{z_{0}}}$ is the virtual potential temperature of reference at $2 \mathrm{~m}$ a.g.1., and $\bar{\theta}_{v}(z)$ is the virtual potential temperature at the height of $z_{5 \mathrm{~m}}$ for the (a) NWs direction range and (b) SEs direction range. The wind speed threshold $V_{\mathrm{T}}$ for $z_{5 \mathrm{~m}}$ is marked using a black triangle in (b).

density currents, and low-level jets (LLJs), which increase local turbulence and may reduce the local stability, even inducing some intermittency. Category $\mathrm{C}$ refers to top-down turbulent events or upside-down boundary layers that enhance downward turbulence into a stable environment, generating regime 3. As the HOST theory and the related intermittency categories were defined for the SBL, here we only consider the nIOPs and illustrate the previous categories selecting appropriate examples.

\subsection{Turbulence intermittency: categories A and B}

During the BLLAST field campaign the occurrence of winds influenced by the complex orography to the south of the site was common (Fig. 3). At this site, they are usually generated after the near-calm conditions of the evening transition, first as shallow drainage flows, and then interrupted by the arrival of a larger and deeper mountain-plain flow with greater values of $V$ (Román-Cascón et al., 2015; Jiménez et al., 2019). The transition between them can cause wind speed oscillations between regime 1 and 2 and shallow wind oscillations within regime 1 , leading to turbulence intermittency of category A and B, respectively. During the BLLAST field campaign both types of transitions were detected, either by the Valimev tower or by both the Valimev and the Skinflow levels. In almost every nIOP one of the different ways of achieving this category of turbulence intermittency is observed. For this study we select the period between 19:00 and 22:00 UTC during the night of 2 July 2011 (nIOP09) (Román-Cascón et al., 2015), as it better represents the intermittency of both of these categories (Fig. 11). The categories can also be found during other nIOPs. Category A can be found in all of the nIOP cases except nIOP10. Category B is not as frequent, occurring for short periods during the nIOPs 01, 02, 03, 04, 05, 07, and 09.

The 2 July 2011 (IOP10) was characterized by an anticyclonic situation over the south of France, leading to weak surface gradients and to near-calm conditions close to the surface in the evening. Thus, at 19:00 UTC the wind speed values are around $0.5 \mathrm{~m} \mathrm{~s}^{-1}$ (Fig. 11a). According to RománCascón et al. (2015), this situation is the foremost scenario for "the appearance of SDFs with a marked SSE-SE component, where stronger winds were encountered at lower levels with maxima close to the surface (around 2-3 $\mathrm{m}$ above ground) and the wind intensity decreasing with height above the maximum". This is the picture of a slight SDF flowing through the nearby gully (Nauta, 2013; Román-Cascón et al., 2015) measured by the Skinflow mast and the Valimev towers, although in Fig. 11 only the $z 30 \mathrm{~m}$ level of Valimev tower is shown (for better clarity). The arrival of this SDF promotes the establishment of a surface temperature inversion (Fig. 11b), with a larger decrease in temperature at the lowest levels. The SDF stage ends around 20:25 UTC with the arrival of a stronger and deeper wind (Fig. 11a) from the southeast, and the MPF stage starts. This increase in wind is more noticeable at high levels, leading to the breaking of the SDF and the potential virtual potential temperature homogenization (Fig.11b).

As Román-Cascón et al. (2015) showed, two different gravity wave events occurred during the SDF stage and the arrival of the MPF. Both events are examples of turbulence intermittency categories. The first corresponds to a wave of almost four cycles with a 20-25 min period approximately between 19:00 and 20:25 UTC. This is an example of category B turbulence intermittency, as the oscillations in wind speed occur for wind speeds below the threshold of each level (see the $V_{\mathrm{T}}$ for each height marked with a coloured horizon- 

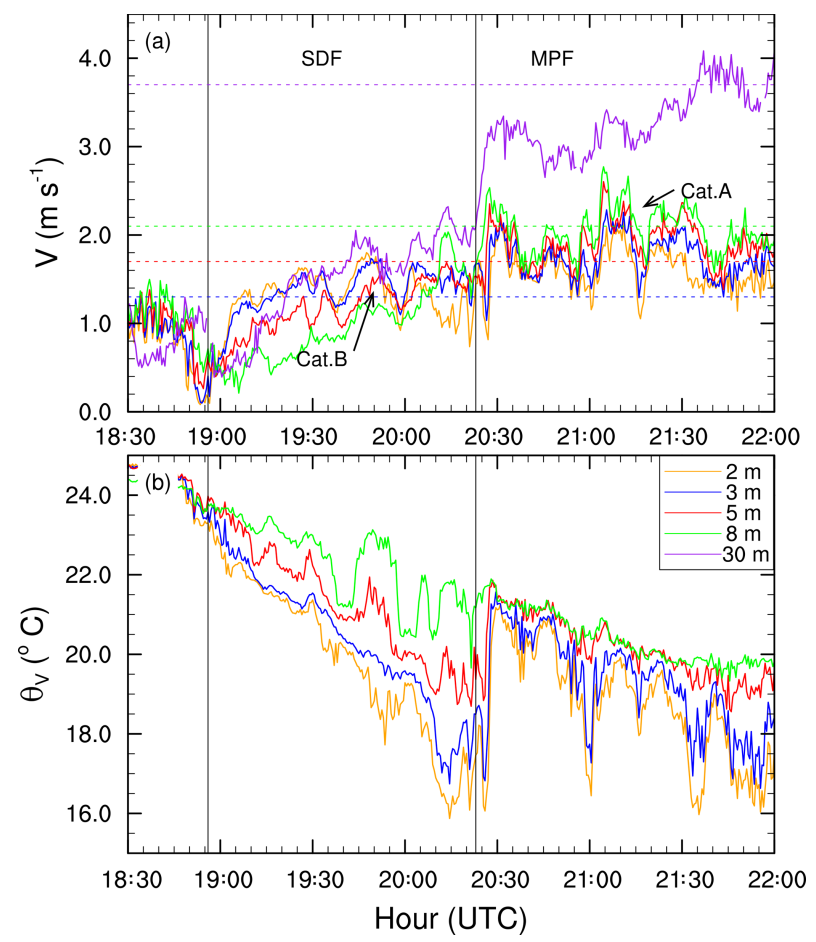

Figure 11. Time series of (a) horizontal wind speed and (b) virtual potential temperature for the 2 July (nIOP09) during the BLLAST field experiment for $z_{2 \mathrm{~m}}, z_{3 \mathrm{~m}}, z_{5 \mathrm{~m}}, z_{8 \mathrm{~m}}$, and $z_{30 \mathrm{~m}}$. The shallow drainage flow (SDF) stage is indicated between 18:55 and 20:20 UTC, and a consecutive mountain-plain flow (MPF) stage thereafter. In the SDF stage there are oscillations within regime 1, which is category $\mathrm{B}$, whereas in the MPF stage there are transitions between regime 1 and regime 2 . The potential temperature is not represented for $z_{30 \mathrm{~m}}$ because there are only thermocouple measurements for the Skinflow mast $\left(z_{2} \mathrm{~m}-z_{8 \mathrm{~m}}\right)$. The wind speed thresholds for several levels are marked with the dashed line to better illustrate the transitions, whereas some transitions between regime 1 and regime 2 are marked with an arrow. The data shown herein are the $30 \mathrm{~s}$ temporal average from sonic anemometers with a frequency of $10 \mathrm{~Hz}$.

tal dashed line in Fig. 11a), within regime 1. The turbulence can be seen clearly for $z_{2} \mathrm{~m}, z_{3 \mathrm{~m}}, z_{5 \mathrm{~m}}$, and $z_{30 \mathrm{~m}}$ (see category B ("Cat. B" arrow in Fig. 11a). Román-Cascón et al. (2015) states that the second event "is characterised by several wind speed oscillations of shorter periods with two notable cycles of greater amplitude from 20:30 to 21:30 UTC'. The wind speed oscillates around the threshold, as an example of category $\mathrm{A}$. There is a transition from regime 1 to 2 and vice versa at $z_{3 \mathrm{~m}}, z_{5 \mathrm{~m}}, z_{8 \mathrm{~m}}$, and $z_{30 \mathrm{~m}}$ ("Cat. A" in Fig. 11a). In addition, when the wind speed is above the threshold, the virtual potential temperature vertical gradients are reduced (Fig. 11b), as it is expected in regime 2 .

\subsection{Turbulence intermittency: category $C$}

Category $\mathrm{C}$ turbulence intermittency refers to the transition between regimes 1 and 3 in the HOST model (Fig. 1). It originates in very stable boundary layers when the main source of turbulence is elevated, and is temporally detached from the surface but intermittently coupled to the surface generating bursts of downward turbulence (Blumen et al., 2001). The origin of this elevated turbulence can be related to the presence of Kelvin-Helmholtz instabilities, density currents, gravity waves, low-level jets, or any other meteorological phenomena that can induce turbulence intermittency (Mahrt, 2014; Udina et al., 2013; Ferreres et al., 2013; Soler et al., 2014)

Usually, category $\mathrm{C}$ turbulence intermittency is characterized by a decrease in $V$, an increase in the variability of $w$ with height, and negative values of the skewness $S$ (Blumen et al., 2001; Sun et al., 2012), meaning a downward transport of turbulence (Mahrt and Vickers, 2002).

In order to illustrate an example of category $C$ turbulence intermittency, we select an event taking place between 03:00 and 04:00 UTC on 26 June 2011, nIOP05. From Fig. 12a we can observe a progressive wind speed decrease in the higher levels of the Valimev tower between 03:10 and 03:50 UTC (see black rectangle in Fig. 12a), associated with an increase on the vertical wind speed variability at $60 \mathrm{~m}$, which has a maximum between 03:45 and 03:55 UTC (Fig. 12b). This maximum increases with height and propagates downward to lower levels with time. This downward turbulence transport is also reflected in negative $S$ values, shown in Fig. 13 for $z_{8 \mathrm{~m}}$ and $z_{60 \mathrm{~m}}$. The period where the skewness is more negative agrees well with the period during which the larger oscillations of $w$ take place (03:50 UTC). All of these characteristics could indicate a turbulence intermittency event corresponding to category $\mathrm{C}$. The event exhibits occasional mixing and a downward transport of turbulence (Mahrt and Vickers, 2002), both suggesting a possible top-down turbulence event. It is relevant to note that this event is not strong enough to arrive to the lowest levels of the Skinflow mast.

Category $\mathrm{C}$ turbulence intermittency does not occur as often as category A and category B, as the number of points within regime 3 in Figs. A1, 8, and 9 shows. These points could sometimes correspond to a top-down event, but not always, as regime 3 can be achieved via accelerations and sharp wind direction shifts (Mahrt et al., 2013).

\section{Conclusions}

In this study we have analysed the HOST theory proposed by Sun et al. (2012) using the nocturnal dataset of the BLLAST campaign, which took place on the "Plateau de Lannemezan", an area located north of the central French Pyrenees. The main objective was to explore the influence of the orography and the weather conditions during the 

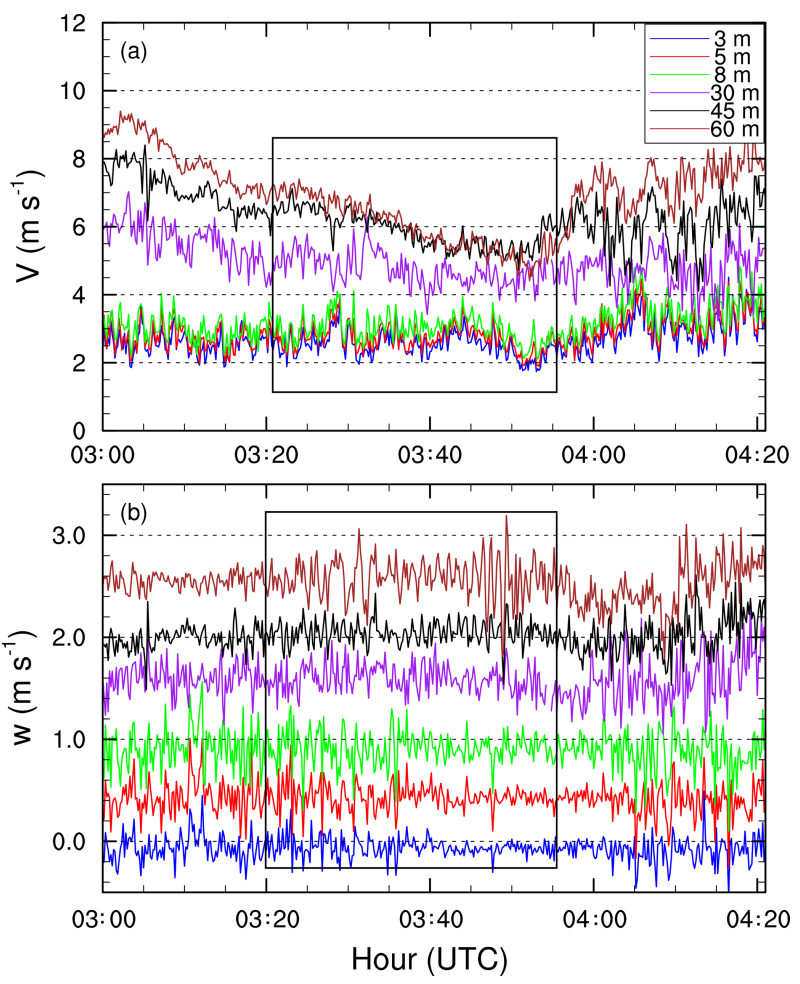

Figure 12. Times series of (a) horizontal wind speed $V$ and (b) vertical wind speed $w$ (incremented $0.5 \mathrm{~m} \mathrm{~s}^{-1}$ for an easy comparison) for 26 June 2011 at $z_{3 \mathrm{~m}}, z_{5 \mathrm{~m}}, z_{8 \mathrm{~m}}, z_{30 \mathrm{~m}}, z_{45 \mathrm{~m}}$, and $z_{60 \mathrm{~m}}$. The black rectangle marks the top-down event. The data shown herein are the $10 \mathrm{~s}$ temporal average from sonic anemometers with a frequency of $10 \mathrm{~Hz}$.

BLLAST campaign on the HOST pattern that was originally defined for a relatively flat area and for fair-weather conditions, the predominant conditions of the CASES-99 field campaign. Here, the analysis was carried out by separating nights into two types: nocturnal IOPs (nIOPs) and the whole nocturnal dataset.

For the nIOPs of the BLLAST campaign, the HOST theory is found to be valid and the turbulence relationships show the different turbulence regimes with a wind speed threshold for each height that locates the transition between the weak wind and weak turbulence intensity generated by local shear (regime 1) and the strong turbulence intensity generated by bulk shear (regime 2). These wind speed thresholds are lower than in Sun et al. (2012); therefore, the bulk shear needed to achieve regime 2 is also lower, due to the greater roughness length of the mountainous terrain linked with the incoming southern flow. Similar results were found by Mahrt et al. (2013) and Bonin et al. (2015) for other locations. These nights are characterized by clear skies and intense radiative cooling where the predominant flow comes from the south-east quadrant corresponding to the arrival of shallow drainage flows to the lower levels and mountain-plain flows later on. These flow circulations generated by the orogra-

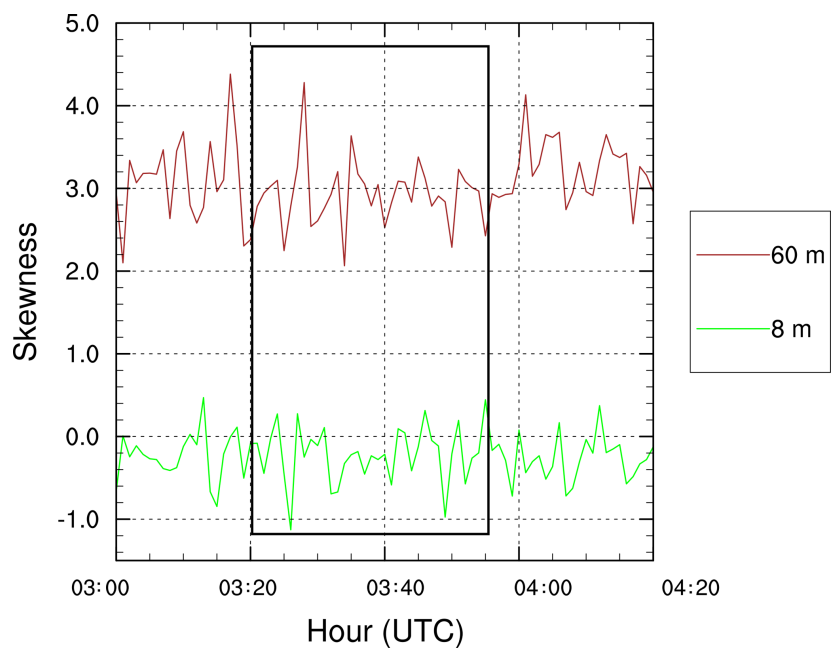

Figure 13. Time evolution of the skewness of the vertical wind component measured between 03:00 and 04:00 UTC on 26 June during the BLLAST field experiment for the $z_{3 \mathrm{~m}}$ and $z_{60 \mathrm{~m}}$ levels. For the sake of clarity, the $60 \mathrm{~m}$ level skewness measurements are increased by $3 \mathrm{~m} \mathrm{~s}^{-1}$. The black rectangle localizes the top-down event. The data shown herein are the 1 min temporal average from sonic anemometers with a frequency of $10 \mathrm{~Hz}$.

phy lead to turbulence enhancement and transitions between regimes, modifying the ideal HOST pattern.

Instead, when the turbulence relationship is analysed for the whole night dataset, results are significantly different, and they become wind direction dependent. The HOST pattern is observed for thermally driven flows, from wind directions between 45 and $235^{\circ}$ (SEs), but it cannot be seen for winds coming from the other directions (NWs). For the NWs flows, the turbulence relationship is almost linear and independent of the vertical temperature gradients. Indeed, when considering the whole night-time dataset the frequency of winds coming from westerly and northerly directions increases, representing the synoptic-scale meteorological situations, in which the HOST pattern is erased mainly due to the fact that the stable boundary layer cannot be developed.

To further investigate the turbulence relationship, we used box plots to provide additional information. Comparing the nIOPs and the SEs flows from the whole nocturnal dataset there are interesting differences: (i) the turbulence intensity tends to increase when we use the whole nocturnal SEs dataset; (ii) the number of outliers increases for the whole nocturnal SEs dataset, as do the number of turbulent events associated with transitions between regimes 1,2 , and 3 . Several points falling in regime 3 are actually associated with sudden wind speed and wind directional shear transitions, reflecting the non-stationary nature of regime 3.

In addition, when HOST is achieved, near-neutral stratification is tied to regime 2, where turbulence is driven by bulk shear. However, when $V<V_{\mathrm{T}}$, stable stratification domi- 
nates, although negative potential temperature differences are present when intermittent turbulence events occur.

Finally, the different transitions between the HOST regimes related to turbulence intermittency (categories A, $\mathrm{B}$, and C) are illustrated for some nIOPs using appropriate examples. Results show that the presence of gravity waves associated with shallow drainage flows and mountain-plain flows create intermittent turbulence that can lead to a transition between regime 1 and regime 2, an example of category A. Local shear can be generated by internal gravity waves of relatively small wind speed amplitude so that the wind speed is lower than the threshold value. As a result, there is an increase of turbulence within regime 1 (Sun et al., 2012), which is the category B turbulence transition. Mahrt (2010) found that with very weak winds and strong stratification (regime 1), turbulence can appear under the presence of gravity waves. These oscillations typically originate within the shallow drainage flow. Category $\mathrm{C}$ may also appear when turbulence created by wind speed or directional shear is diffused downward, toward a stable environment.

Present and future work related to the knowledge of the flow circulation in BLLAST site will help further the understanding of the results obtained herein. In addition, a deeper and longer-term study of the HOST theory at other locations considering mountain influenced sites and complex terrain areas would be desirable so that our outcomes could be generalized.
Data availability. BLLAST field campaign data are accessible on the BLLAST operation centre sedoo website (https://doi.org/10.6096/BLLAST.60MTOWER.METEO, Lab. d'aerologie, 2019; https://doi.org/10.6096/BLLAST.DivergenceSite, MAQ Wageningen University, 2019). 


\section{Appendix A: Box plot analysis during nIOPs}

This appendix is devoted to complementing Sect. 3, showing the relationship between the $V_{\mathrm{TKE}}$ and $V$ for the nIOP cases using box plot analysis (Fig. A1). It can be clearly seen that the results obtained herein display the same HOST theory as in Sun et al. (2012) for the CASES-99 field campaign.
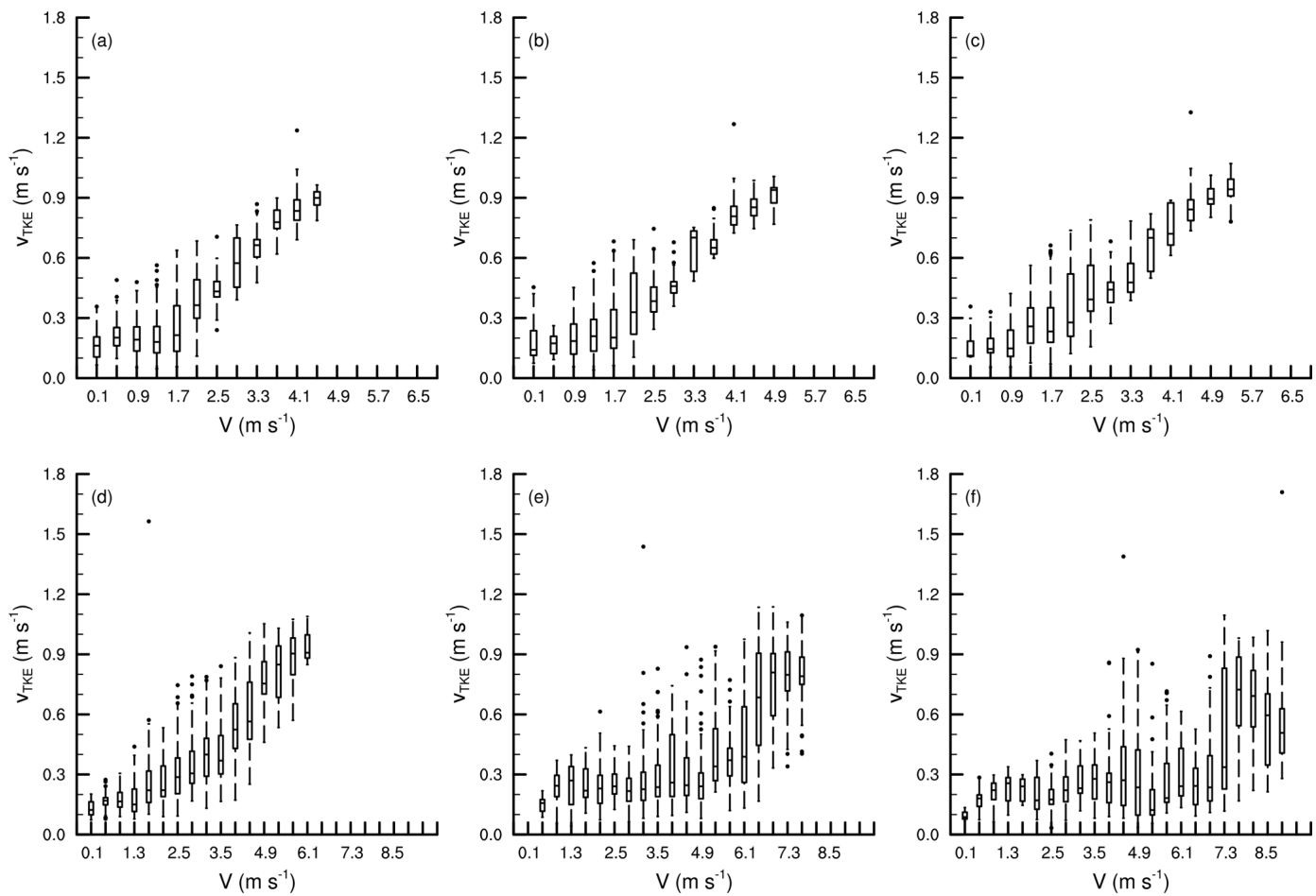

Figure A1. Box plots of the relationship between the bin-averaged turbulence strength $V_{\text {TKE }}$ and the wind speed $V$ for the nIOPs of the BLLAST field campaign. The maximum whisker length is proportional to 1.5 times the third and first quartile difference, or the inter-quartile range (1.5 · IQR). Data correspond to the Skinflow mast and to the Valimev tower at different heights: (a) $z_{33 \mathrm{~m}}$, (b) $z_{5 \mathrm{~m}}$, and (c) $z_{8 \mathrm{~m}}$ for the Skinflow mast levels, and (d) $z_{30 \mathrm{~m}}$, (e) $z_{45 \mathrm{~m}}$, and (f) $z_{60 \mathrm{~m}}$ for the Valimev tower levels. 
Author contributions. ML supplied access to the whole dataset and provided first hand insight to the BLLAST site and its phenomena. EN carried out some data treatment for the Skinflow mast and provided useful and precise advice on conceptual matters. JS provided very helpful information on the HOST theory and ideas for improvement on the initial idea. JB, along with all co-authors, provided help regarding the paper structure and general advice on turbulence. MRS and MU played a crucial role in the processes of crafting this paper from scratch. JYD developed the data process, the analysis of the results, and summarized and expressed them in this article.

Competing interests. The authors declare that they have no conflict of interest.

Acknowledgements. The BLLAST field experiment was made possible due to the support and contributions of several institutions: INSU-CNRS (Institut National des Sciences de l'Univers, Centre national de la Recherche Scientifique, LEFE-IDAO program), Météo-France, Observatoire Midi-Pyrénées (University of Toulouse), EUFAR (EUropean Facility for Airborne Research), and COST ES0802 (European Cooperation in Science and Technology). The field experiment would not have occurred without the contributions of all of the participating European and American research groups, who all contributed a significant amount. The BLLAST field experiment was hosted by the instrumented site of Centre de Recherches Atmosphériques, Lannemezan, France (Observatoire Midi-Pyrénées, Laboratoire d'Aérologie). Its 60 m ("Valimev") tower was partly supported by the POCTEFA/FLUXPYR European program. BLLAST data are managed by SEDOO from the Observatoire Midi-Pyrénées. We would also like to thank the following people, who were responsible for the instruments and data used in his study: Fabienne Lohou, PI of surface measurements at the BLLAST site; Frédérique Saïd and Solène Derrien for the $60 \mathrm{~m}$ instrumentation and data; and Eric Pardyjak and Daniel Alexander for the $8 \mathrm{~m}$ ("Skinflow") tower. We further acknowledge the P2OA instrumented site, as the Centre de Recherches Atmosphériques of Lannemezan is part of an instrumented platform called Pyrenean Platform of the Observation of the Atmosphere (P2OA) (http://p2oa.aero.obs-mip.fr, last access: 18 July 2019). P2OA facilities and staff are funded and supported by the Observatoire Midi-Pyrénées (University of Toulouse, France) and CNRS (Centre National de la Recherche Scientifique). Jielun Sun is supported by NSF while she serves at NSF. Any opinions, findings and conclusions, or recommendations expressed in this publication do not necessarily reflect the views of the NSF.

Financial support. This research has been supported by the Spanish government (grant nos. CGL2015-65627-C3-2-R and MINECO CGL2016-81828-REDT).

Review statement. This paper was edited by Stefano Galmarini and reviewed by two anonymous referees.

\section{References}

Acevedo, O. C., Mahrt, L., Puhales, F. S., Costa, F. D., Medeiros, L. E., and Degrazia, G. A.: Contrasting structures between the decoupled and coupled states of the stable boundary layer, Q. J. Roy. Meteor. Soc., 142, 693-702, 2016.

Andreae, M. O., Acevedo, O. C., Araùjo, A., Artaxo, P., Barbosa, C. G. G., Barbosa, H. M. J., Brito, J., Carbone, S., Chi, X., Cintra, B. B. L., da Silva, N. F., Dias, N. L., Dias-Júnior, C. Q., Ditas, F., Ditz, R., Godoi, A. F. L., Godoi, R. H. M., Heimann, M., Hoffmann, T., Kesselmeier, J., Kœnemann, T., Krüger, M. L., Lavric, J. V., Manzi, A. O., Lopes, A. P., Martins, D. L., Mikhailov, E. F., Moran-Zuloaga, D., Nelson, B. W., Nölscher, A. C., Santos Nogueira, D., Piedade, M. T. F., Pöhlker, C., Pöschl, U., Quesada, C. A., Rizzo, L. V., Ro, C.-U., Ruckteschler, N., Sá, L. D. A., de Oliveira Sá, M., Sales, C. B., dos Santos, R. M. N., Saturno, J., Schöngart, J., Sörgel, M., de Souza, C. M., de Souza, R. A. F., Su, H., Targhetta, N., Tóta, J., Trebs, I., Trumbore, S., van Eijck, A., Walter, D., Wang, Z., Weber, B., Williams, J., Winderlich, J., Wittmann, F., Wolff, S., and Yáñez-Serrano, A. M.: The Amazon Tall Tower Observatory (ATTO): overview of pilot measurements on ecosystem ecology, meteorology, trace gases, and aerosols, Atmos. Chem. Phys., 15, 10723-10776, https://doi.org/10.5194/acp-15-10723-2015, 2015.

Barneoud, P., Beck, S., Lafrique, P., and Lagnoux, B.: Climatologie sur le site instrumenté du Laboratoire d'Aérologie, 2010.

Blay-Carreras, E., Pardyjak, E. R., Pino, D., Alexander, D. C., Lohou, F., and Lothon, M.: Countergradient heat flux observations during the evening transition period, Atmos. Chem. Phys., 14, 9077-9085, https://doi.org/10.5194/acp-14-9077-2014, 2014.

Blumen, W. ., Banta, R., Burns, S., Fritts, D., Newson, R., Poulos, G., and Sun, J.: Turbulence statistics of a Kelvin-Helmholtz billow event observed in the night-time boundary layer during the Cooperative Atmosphere-Surface Exchange Study field program, Dynamic of Atmospheres and Oceans, 34, 189-204, 2001.

Bonin, T. A., Blumberg, W. G., Klein, P. M., and Chilson, P. B.: Thermodynamic and turbulence characteristics of the southern great plains nocturnal boundary layer under differing turbulent regimes, Bound.-Lay. Meteorol., 157, 401-420, 2015.

Cuxart, J. and Jiménez, M.: Mixing processes in a nocturnal lowlevel jet: An LES study, J. Atmos. Sci., 64, 1666-1679, 2007.

De Coster, O., Pietersen, H. P., Lohou, F., Hartogensis, O., and Moene, A.: BLLAST-uniform processing of Eddy-Covariance data, Internship Report Meteorology and Climatology, Wageningen University and Research Center, 990, 33 pp., 2011.

Ferreres, E., Soler, M., and Terradellas, E.: Analysis of turbulent exchange and coherent structures in the stable atmospheric boundary layer based on tower observations, Dynam. Atmos. Oceans, 64, 62-78, 2013.

Jimenez, M. and Cuxart, J.: A study on the nocturnal flows generated in the north side of the Pyrenees, Atmos. Res., 145, 244 254, 2014.

Jiménez, M. A., Cuxart, J., and Martínez-Villagrasa, D.: Influence of a valley exit jet on the nocturnal atmospheric boundary layer at the foothills of the Pyrenees, Q. J. Roy. Meteor. Soc., 145, 356-375, 2019.

Lab. d'aerologie: $60 \mathrm{~m}$ tower/Meteorological parameters, https://doi.org/10.6096/BLLAST.60MTOWER.METEO, last access: 18 July 2019. 
Lin, J.-T. and Pao, Y.-H.: Wakes in stratified fluids, Annu. Rev. Fluid Mech., 11, 317-338, 1979.

Lothon, M., Lohou, F., Pino, D., Couvreux, F., Pardyjak, E. R., Reuder, J., Vilà-Guerau de Arellano, J., Durand, P., Hartogensis, O., Legain, D., Augustin, P., Gioli, B., Lenschow, D. H., Faloona, I., Yagüe, C., Alexander, D. C., Angevine, W. M., Bargain, E., Barrié, J., Bazile, E., Bezombes, Y., Blay-Carreras, E., van de Boer, A., Boichard, J. L., Bourdon, A., Butet, A., Campistron, B., de Coster, O., Cuxart, J., Dabas, A., Darbieu, C., Deboudt, K., Delbarre, H., Derrien, S., Flament, P., Fourmentin, M., Garai, A., Gibert, F., Graf, A., Groebner, J., Guichard, F., Jiménez, M. A., Jonassen, M., van den Kroonenberg, A., Magliulo, V., Martin, S., Martinez, D., Mastrorillo, L., Moene, A. F., Molinos, F., Moulin, E., Pietersen, H. P., Piguet, B., Pique, E., Román-Cascón, C., Rufin-Soler, C., Saïd, F., Sastre-Marugán, M., Seity, Y., Steeneveld, G. J., Toscano, P., Traullé, O., Tzanos, D., Wacker, S., Wildmann, N., and Zaldei, A.: The BLLAST field experiment: Boundary-Layer Late Afternoon and Sunset Turbulence, Atmos. Chem. Phys., 14, 10931-10960, https://doi.org/10.5194/acp-1410931-2014, 2014.

Mahrt, L.: Stratified atmospheric boundary layers, Bound.-Lay. Meteorol., 90, 375-396, 1999.

Mahrt, L.: Computing turbulent fluxes near the surface: Needed improvements, Agr. Forest Meteorol., 150, 501-509, 2010.

Mahrt, L.: Stably stratified atmospheric boundary layers, Annu. Rev. Fluid Mech., 46, 23-45, 2014.

Mahrt, L.: Stably stratified flow in a shallow valley, Bound.-Lay. Meteorol., 162, 1-20, 2017.

Mahrt, L. and Vickers, D.: Contrasting vertical structures of nocturnal boundary layers, Bound.-Lay. Meteorol., 105, 351-363, 2002.

Mahrt, L., Thomas, C., Richardson, S., Seaman, N., Stauffer, D., and Zeeman, M.: Non-stationary generation of weak turbulence for very stable and weak-wind conditions, Bound.-Lay. Meteorol., 147, 179-199, 2013.

MAQ Wageningen University: Divergence site, https://doi.org/10.6096/BLLAST.DivergenceSite, last access: 18 July 2019.

Nauta, L.: Shallow drainage flows over light sloping terrain during BLLAST 2011: Two case studies, Master's thesis, Meteorology and air quality group at the Wageningen University, supervised by Dr. Ir. Oscar Hartogenesis, 2013.

Newsom, R. K. and Banta, R. M.: Shear-flow instability in the stable nocturnal boundary layer as observed by Doppler lidar during CASES-99, J. Atmos. Sci., 60, 16-33, 2003.

Nilsson, E., Lohou, F., Lothon, M., Pardyjak, E., Mahrt, L., and Darbieu, C.: Turbulence kinetic energy budget during the afternoon transition - Part 1: Observed surface TKE budget and boundary layer description for 10 intensive observation period days, Atmos. Chem. Phys., 16, 8849-8872, https://doi.org/10.5194/acp16-8849-2016, 2016.

Poulos, G. S., Blumen, W., Fritts, D. C., Lundquist, J. K., Sun, J., Burns, S. P., Nappo, C., Banta, R., Newsom, R., Cuxart, J., Terradellas, E., Balsley, B., and Jensen, M.: CASES-99: A comprehensive investigation of the stable nocturnal boundary layer, B. Am. Meteorol. Soc., 83, 555-581, 2002.

Román-Cascón, C., Yagüe, C., Arrillaga, J., Lothon, M., Pardyjak, E., Lohou, F., Inclán, R., Sastre, M., Maqueda, G., Derrien, S., et al.: Comparing mountain breezes and their impacts on $\mathrm{CO}_{2}$ mixing ratios at three contrasting areas, Atmos. Res., 221, 111126, 2019.

Román-Cascón, C., Yagüe, C., Mahrt, L., Sastre, M., Steeneveld, G.-J., Pardyjak, E., van de Boer, A., and Hartogensis, O.: Interactions among drainage flows, gravity waves and turbulence: a BLLAST case study, Atmos. Chem. Phys., 15, 9031-9047, https://doi.org/10.5194/acp-15-9031-2015, 2015.

Said, F., Derrien, S., Pique, E., Abadie, M., Meyerfeld, Y., Jarnot, C., Martin, J., Bezombes, Y., Lohou, F., Lothon, M., Rechal, R., and Bargain, E.: POCTEFA/FluxPyr and BLLAST Campistrous mast June 2011, available at: http://bllast.sedoo.fr/database/source/displayDataCorps.php?pi= Fabienne.Lohou@aero.obs-mip.fr\&rep=../data/FREE/Ground_ Station/60_m_Tower/fiches_Meteorologicalparameters/, 2011a.

Said, F., Derrien, S., Pique, E., Abadie, M., Meyerfeld, Y., Jarnot, C., Martin, J., Bezombes, Y., Lohou, F., Lothon, M., Rechal, R., and Bargain, E.: POCTEFA/FluxPyr and BLLAST Campistrous mast July 2011, available at: http://bllast.sedoo.fr/database/source/displayDataCorps.php?pi= Fabienne.Lohou@aero.obs-mip.fr\&rep=../data/FREE/Ground_ Station/60_m_Tower/fiches_Meteorologicalparameters/, 2011b.

Soler, M., Infante, C., Buenestado, P., and Mahrt, L.: Observations of nocturnal drainage flow in a shallow gully, Bound.-Lay. Meteorol., 105, 253-273, 2002.

Soler, M., Udina, M., and Ferreres, E.: Observational and numerical simulation study of a sequence of eight atmospheric density currents in northern Spain, Bound.-Lay. Meteorol., 153, 195-216, 2014.

Sun, J.: Vertical variations of mixing lengths under neutral and stable conditions during CASES-99, J. Appl. Meteorol. Clim, 50, 2030-2041, 2011.

Sun, J., Burns, S. P., Lenschow, D. H., Banta, R., Newsom, R., Coulter, R., Frasier, S., Ince, T., Nappo, C., Cuxart, J., Blumen, W., Lee, X., Hu, X.-Z.: Intermittent turbulence associated with a density current passage in the stable boundary layer, Bound.-Lay. Meteorol., 105, 199-219, 2002.

Sun, J., Lenschow, D. H., Burns, S. P., Banta, R. M., Newsom, R. K., Coulter, R., Frasier, S., Ince, T., Nappo, C., Balsley, B. B., Jensen, M., Mahrt, L., Miller, D., and Skelly, B.: Atmospheric disturbances that generate intermittent turbulence in nocturnal boundary layers, Bound.-Lay. Meteorol., 110, 255-279, 2004.

Sun, J., Mahrt, L., Banta, R., and Pichugina, Y. L.: Turbulence regimes and turbulence intermittency in the stable boundary layer during CASES99, J. Atmos. Sci., 69, 338-351, 2012.

Sun, J., Lenschow, D. H., LeMone, M. A., and Mahrt, L.: The role of large-coherent-eddy transport in the atmospheric surface layer based on CASES-99 observations, Bound.-Lay. Meteorol., 160, 83-111, 2016.

Terradellas, E., Soler, M., Ferreres, E., and Bravo, M.: Analysis of oscillations in the stable atmospheric boundary layer using wavelet methods, Bound.-Lay. Meteorol., 114, 489-518, 2005.

Udina, M., Soler, M., Viana, S., and Yagüe, C.: Model simulation of gravity waves triggered by a density current, Q. J. Roy. Meteor. Soc., 139, 701-714, 2013.

Udina, M., Sun, J., Kosović, B., and Soler, M. R.: Exploring vertical turbulence structure in neutrally and stably stratified flows using the weather research and forecasting-large-eddy simulation (WRF-LES) model, Bound.-Lay. Meteorol., 161, 355-374, 2016. 
Viana, S., Terradellas, E., and Yagüe, C.: Analysis of gravity waves generated at the top of a drainage flow, J. Atmos. Sci., 67, 39493966, 2010.

Wyngaard, J. C.: Turbulence in the Atmosphere, Cambridge University Press, Cambridge, UK, 393 pp, 2010.
Zilitinkevich, S., Elperin, T., Kleeorin, N., and Rogachevskii, I.: Energy-and flux-budget (EFB) turbulence closure model for stably stratified flows, Part I: Steady-state, Homogeneous regimes, 11-35, 2007. 